Running head: ATTENTION-MEMORY BIAS INTERACTIONS IN DEPRESSION

\title{
Mapping dynamic interactions among cognitive biases in depression
}

\author{
Jonas Everaert ${ }^{1}$, Amit Bernstein ${ }^{2}$, Jutta Joormann ${ }^{3}$ \& Ernst H. W. Koster ${ }^{1}$ \\ ${ }^{1}$ Ghent University, Belgium \\ ${ }^{2}$ University of Haifa, Israel \\ ${ }^{3}$ Yale University, United States of America
}

* Corresponding author:

Jonas Everaert, $\mathrm{PhD}$

Ghent University

Department of Experimental Clinical and Health Psychology

Henri Dunantlaan 2, 9000 Ghent, Belgium

Phone: 0032485405992

E -mail: jonas.everaert@gmail.com 


\begin{abstract}
Depression is theorized to be caused in part by biased cognitive processing of emotional information. Yet, prior research has adopted a reductionist approach that does not characterize how biases in cognitive processes such as attention and memory work together to confer risk for this complex multifactorial disorder. Grounded in affective and cognitive science, we highlight four mechanisms to understand how attention biases, working memory difficulties, and long-term memory biases interact and contribute to depression. We review evidence for each mechanism and highlight time- and context-dependent dynamics. We outline methodological considerations and recommendations for research in this area. We conclude with directions to advance the understanding of depression risk, cognitive training interventions, and transdiagnostic properties of cognitive biases and their interactions.
\end{abstract}

KEYWORDS: Attention; Working memory; Long-term memory; Executive control; Cognitive biases; Depression. 


\section{Introduction}

How people process emotional information has long been theorized to play a crucial role in the onset, maintenance, and recurrence of depression (for reviews, see Gotlib \& Joormann, 2010; LeMoult \& Gotlib, 2018; Mathews \& Macleod, 2005). Theories postulate that depression is caused in part by biases in basic cognitive processes - the ways people attend to and remember personallyrelevant and emotional events (Beck \& Haigh, 2014; De Raedt \& Koster, 2010; Ingram, 1984; Joormann, Yoon, \& Zetsche, 2007; Williams et al., 1997). ${ }^{1}$ In line with theoretical predictions, systematic reviews and meta-analyses have provided some evidence for two types of attention biases in depression, namely an attention bias toward negative self-relevant information (Armstrong \& Olatunji, 2012; Peckham, McHugh, \& Otto, 2010) and an attenuated attention bias toward positive or rewarding stimuli (Armstrong \& Olatunji, 2012; Winer \& Salem, 2016). Furthermore, extensive research has linked depression to difficulties in working memory operations that result in biased representation of negative vs. positive material (Joormann, 2010; Koster, De Lissnyder, Derakshan, \& De Raedt, 2011; Schweizer et al., 2019). Finally, metaanalyses suggest that depression is characterized by enhanced retrieval of self-referent negative and diminished retrieval of positive representations from long-term memory (Gaddy \& Ingram, 2014; Matt, Vázquez, \& Campbell, 1992).

Importantly, these cognitive biases may not be an epiphenomenon of depression. Studies suggest that biases in attention, working memory, and long-term memory may causally contribute to depressive symptoms (Beevers, Clasen, Enock, \& Schnyer, 2015; Schweizer, Grahn, Hampshire,

\footnotetext{
${ }^{1}$ Depression has been linked to cognitive deficits in processing speed, learning and memory, autobiographical memory, shifting, and IQ (Ahern \& Semkovska, 2017). While these cognitive deficits normalize during remission of depression, biases of attention and memory as well as executive control difficulties may persist after a depressive episode (LeMoult \& Gotlib, 2018). Therefore, this article focuses on interactions among emotional attention and memory processes in an attempt to better understand the mechanisms underlying risk to depression.
} 
Mobbs, \& Dalgleish, 2013), predict the longitudinal course of depression severity (Beeney \& Arnett, 2008; Johnson, Joormann, \& Gotlib, 2007; Price et al., 2016), occur in individuals who are at risk for developing depression (Vrijsen, Becker, et al., 2014; Zvielli, Vrijsen, Koster, \& Bernstein, 2016), affect stress reactivity and recovery (Clasen, Wells, Ellis, \& Beevers, 2013; Ellenbogen, Schwartzman, Stewart, \& Walker, 2002; Sanchez, Vazquez, Marker, LeMoult, \& Joormann, 2013), and hamper effective regulation of negative emotions (for a review, see Joormann \& Vanderlind, 2014). Together, research indicates that biased cognitive processing of emotional information is critical to understanding risk for depression.

To-date, research has largely focused on elucidating the role of individual cognitive biases in depression. Studying biases in attention and memory as distinct phenomena has been instrumental to understanding these cognitive processes and their individual role in depression. Yet, this approach cannot characterize how cognitive biases work together to confer risk for complex disorders such as depression (Aue \& Okon-Singer, 2015; Everaert, Koster, \& Derakshan, 2012; Hertel \& Brozovich, 2010; Hirsch, Clark, \& Mathews, 2006; Lau \& Waters, 2017; Wittenborn, Rahmandad, Rick, \& Hosseinichimeh, 2016). Even individual symptoms of depression (e.g., sad mood, hopelessness) and other features of maladaptation (e.g., impaired stress recovery, difficulties regulating negative mood) are unlikely caused and/or maintained by single factors or processes (Borsboom, 2017; Hankin, 2012; Kraemer, Stice, Kazdin, Offord, \& Kupfer, 2001). A limited understanding of the interactions among cognitive biases may hamper a more complete understanding of the cognitive foundations of depression, and consequently, potential approaches to its treatment.

Elucidating the mechanisms or systemic interactions among these cognitive biases may be directly informed by recent advances in the fields of cognitive and affective science. Extensive research in these fields has provided evidence that attention, working memory, and long-term 
memory are highly interactive processes that - through their interactions - shape online information-processing. Specifically, cognitive research has well-documented that attention influences the encoding of information into working memory and long-term memory (Awh, Vogel, \& Oh, 2006; Chun, Golomb, \& Turk-Browne, 2011; Luck \& Gold, 2008), attention modulates the retrieval of information from long-term memory (Chun et al., 2011; Chun \& Turk-Browne, 2007), and both working memory and long-term memory representations shape attention allocation (Hasson, Chen, \& Honey, 2015; Hutchinson \& Turk-Browne, 2012; Todd \& Manaligod, 2017). Furthermore, research from affective sciences has revealed that attention enhances long-term memory for emotional information through its influence on both encoding and retrieval processes (see Talmi, 2013, for a review), and that emotional memories may, in turn, guide selective attention processes (Schupp, Kirmse, Schmälzle, Flaisch, \& Renner, 2016).

Grounded in this basic research, we identified four mechanisms that may be important to understanding how attention biases, working memory difficulties, and long-term memory biases work together and, thereby, contribute to depression: (1) attention biases during memory encoding modulate long-term memory biases; (2) attention biases during memory retrieval modulate longterm memory biases; (3) long-term memory biases guide the allocation of attention; and (4) working memory difficulties modulate the interactions between biases of attention and long-term memory. These four mechanisms likely occur in mental disorders such as depression because they reflect normal interactions among fundamental cognitive processes, but with these processes becoming increasingly biased toward negative vs. positive information as depressive symptom severity increases (Gibb, Alloy, Abramson, Beevers, \& Miller, 2004; Liu et al., 2018).

Below, we begin by describing core properties of attention and memory as well as biases in these cognitive processes in depression. We then present each of the four theorized attentionmemory mechanisms and review emerging empirical insights from research on depression in adult 
samples. Next, to further characterize and understand these mechanisms and their systemic properties, we highlight their time- and context-dependent dynamics. Then, we outline methodological considerations and recommendations for empirical research in this field of interest. We conclude with promising directions to uncover how cognitive biases may translate to depression, advance the development of cognitive training interventions, as well as establish transdiagnostic features of cognitive biases and their interactions.

\section{Properties of attention and memory processes}

\subsection{Attention: Selection and modulation}

Taxonomies of basic cognitive processes have guided the conceptualization and operationalization of attention and memory biases in psychopathology. Attention helps to prioritize the most relevant sources of information. It involves operations that serve the selection of stimuli that compete for access to limited cognitive resources (i.e. attention selection) and operations that determine how extensively stimuli are processed (i.e. attention modulation) (Chun et al., 2011; Petersen \& Posner, 2012). Attention modulation determines the degree of processing after a stimulus has been selected (Chun et al., 2011). Distinguishing these operations has proven to be important in characterizing attention bias in depression. Research suggests that depression is more often linked to biases at later stages of processing in attention modulation (De Raedt \& Koster, 2010), with studies showing that depressed individuals show reduced maintenance of attention to positive information and increased maintenance of attention to negative information (Armstrong \& Olatunji, 2012).

Attention selects and modulates information from both external and internal sources (Chun et al., 2011; Dixon, Fox, \& Christoff, 2014). This implies that attention biases may determine which stimuli from one's sensory environment (e.g., angry facial expressions from your partner) as well as which mental representations (e.g., emotional memories and thoughts) are selected and how this 
information is subsequently processed (e.g., to understand the implications for the current situation). Existing research indicates that depression is linked to biases in both domains (for a review, see Mennen, Norman, \& Turk-Browne, 2019). As noted, depression is linked to biases in attention when processing external emotional stimuli as well as biases in the contents (i.e., representations) of working memory that involve increased internal attention to negative vs. positive mental representations (Joormann, 2010; Koster et al., 2011; Schweizer et al., 2019). Indeed, by recruiting working memory operations, internal attention biases are intimately linked to memory processes.

\subsection{Memory: Explicit and implicit systems}

Memory refers to a collection of phenomena traditionally divided into explicit and implicit systems (Chun et al., 2011; Hutchinson \& Turk-Browne, 2012). Explicit and implicit memory depend on different cognitive and neural architectures that permit their independent operation (Dudukovic \& Wagner, 2006). Explicit memory refers to storage systems that represent knowledge either in a consciously accessible manner in long-term memory (LTM; e.g., semantic memory for factual information and episodic memory for specific events, accessed via recall or recognition) or as information that is temporarily activated or "held online" in working memory (WM). WM refers to a temporary and limited-capacity store that operates at the intersection between external (e.g., sensory information) and internal (e.g., LTM representations) sources of information (Chun et al., 2011; Dixon et al., 2014). Implicit LTM refers to non-consciously accessible knowledge that is expressed through changes in behavior or performance (e.g., perceptual or associative learning).

Regarding LTM biases in depression, meta-analytic evidence indicates that depression is related to better explicit and implicit memory for negative vs. positive information (Gaddy \& Ingram, 2014; Matt et al., 1992). With respect to WM, depression is characterized by the biased representation of negative vs. positive material in WM (Joormann, 2010; Koster et al., 2011; Schweizer et al., 2019). This skewed representation of emotional material results from difficulties 
in executive control. Adopting models from cognitive science (e.g., Miyake \& Friedman, 2012), three executive control operations have been identified and hamper efficient WM functioning: difficulties in inhibiting negative material from entering WM (Goeleven et al., 2006; Joormann, 2004), difficulties in shifting between negative and neutral mental sets (De Lissnyder et al., 2010), and difficulties in updating WM by removing no-longer relevant negative information (Levens \& Gotlib, 2010). These difficulties in working memory operations may hamper flexible adaptation of cognition and behavior in depression (Grahek, Everaert, Krebs, \& Koster, 2018).

\section{Mechanisms of attention and memory interactions in depression}

Figure 1 provides a schematic overview of the mechanisms and features of dynamic interactions among biases in attention and memory processes in depression.

\subsection{Attention bias during memory encoding modulates LTM bias}

The question of how attention biases influence encoding (i.e., the process of creating a new mental representations that can be stored within memory systems) of emotional information and thereby modulate explicit LTM in depression has received considerable empirical attention. Initial work examined the role of attention biases during encoding in enhancing LTM bias by presenting an attention bias task (e.g., exogenous cueing task, free viewing eye-tracking task) followed by a memory task probing recall or recognition of the presented stimuli (Ellis, Beevers, \& Wells, 2011; Koster, De Raedt, Leyman, \& De Lissnyder, 2010). By using the same stimulus materials across tasks, these studies test whether attention bias skews encoding in favor of negative information and how this is associated with a negative LTM bias. The results of these studies revealed that greater attention bias to negative words (during elaborate processing stages) was related to improved recall of these negative words (Koster et al., 2010). In addition, less attention to positive words was associated with less accurate recognition of these items (Ellis et al., 2011). These initial observations in samples of individuals with self-reported depressive symptoms indicate that 
attention biases during encoding enhance later memory for negative material and impair memory for positive material. These findings align with evidence from cognitive science showing that divided (vs. full) attention during encoding results in diminished explicit LTM for previously encountered information (for reviews, see Chun \& Turk-Browne, 2007; Turk-Browne, Golomb, \& Chun, 2013) as well as research from affective science showing that attention allocation toward emotional information during encoding (partly) explains subsequent enhanced recall of emotional information (Pottage \& Schaefer, 2012; Talmi, 2013).

Recently, researchers have started to investigate how biases in different operations of attention modulate the encoding of emotional self-referent meanings and LTM bias. In one study, participants with varying self-reported levels of depressive symptom severity were asked to unscramble emotional sentences in either a positive or negative manner (e.g., "born winner am loser a I" into either "I am a born loser" or "I am a born winner") (Everaert, Duyck, \& Koster, 2014). When unscrambling the sentences, biases in overt attention toward negative (e.g., "loser") vs. positive (e.g., "winner”) words were measured using eye-tracking. A subsequent free recall task prompted participants to recollect the constructed self-referent meanings and served as a measure of memory bias. Bias in attention selection toward negative vs. positive words was indirectly related to better LTM for negative vs. positive meanings via a higher proportion of generated negative vs. positive meanings. Moreover, attention modulation bias toward negative vs. positive words was directly related to a congruent memory bias. These observations add to prior research by showing that biases in distinct operations of attention - selection and modulation - may play a different role in encoding emotional information in LTM.

Extending this work on explicit LTM, a recent study examined whether symptoms of anhedonia are related to negative biases in attention and implicit LTM (Salem, Winer, \& Nadorff, 2017). A convenience sample of participants with varying depressive symptom levels completed 
the attention dot probe task followed by a two-alternative forced-choice recognition task to assess implicit memory for stimuli that were presented during the attention task. In the two-alternative forced-choice recognition task, participants were briefly presented with a stimulus word from the dot probe task, which was then masked and replaced by two response choices (including the target word and a foil). Participants were instructed to select the word that was presented during the attention task. Though effect sizes were small, implicit memory bias moderated the relation between attention bias and symptoms of anhedonia. Negative attention bias was associated with anhedonia only at high levels of implicit memory bias. In sum, research suggests that attention bias during encoding modulates both explicit and implicit memory bias. Yet, attention bias may not influence implicit memory to the same degree as it influences explicit LTM bias.

\subsection{Attention bias during memory retrieval modulates LTM bias}

In depression, attention biases may selectively enhance LTM even after encoding by altering how stored items are retrieved from LTM. Retrieval refers to a process of recollecting or accessing mental representations that have been encoded and stored in memory. Clinical research on how attention biases could modulate retrieval of emotional information and enhance LTM bias in depression is lacking, but can be guided by findings from basic research. While neuroimaging research has suggested the role of top-down attention during memory retrieval (e.g., Guerin, Robbins, Gilmore, \& Schacter, 2012), behavioral research has yielded less conclusive associations. On the one hand, several studies using a concurrent divided attention task have found small effects on free recall, indicating that retrieval can occur successfully in the absence of focused attention (Craik, Eftekhari, \& Binns, 2018; Naveh-Benjamin, Kilb, \& Fisher, 2006). On the other hand, other studies have observed that dividing attention during LTM retrieval significantly reduces memory performance, suggesting that retrieval is an attention-demanding process (Fernandes \& Moscovitch, 2002; Rohrer \& Pashler, 2003). To rectify these seemingly conflicting findings, scholars proposed 
that the extent to which attention during LTM retrieval affects memory performance depends on whether retrieval relies on recollection or familiarity (Dudukovic, DuBrow, \& Wagner, 2009). Recollection (i.e., retrieval of specific details about the prior occurrence of an item) and familiarity (i.e., a sense of having encountered an item without retrieving specific details) rely on at least partly different cognitive and neural mechanisms (Yonelinas, Aly, Wang, \& Koen, 2010). Accordingly, whereas recollection is attention-demanding (i.e., more explicit) familiarity can be largely automatic (i.e., more implicit) (Jacoby, 1991). As such, dividing attention during memory retrieval would reduce memory for recollected items but leave familiarity-based retrieval intact. Indeed, basic cognitive studies have provided empirical support for this hypothesis (Hicks \& Marsh, 2000).

The question of how attention modulates emotional LTM retrieval has gained considerable interest (for a review, see Talmi, 2013). It is notable that behavioral studies in this area have also been mixed. For example, one study observed that the emotion-enhanced memory effect (i.e., better memory for emotional vs. neutral content) was not influenced by dividing attentional resources during retrieval (Clark-Foos \& Marsh, 2008), whereas another study reported that the enhancement effect disappeared with divided attention (Maddox, Naveh-Benjamin, Old, \& Kilb, 2012). It may be that the noted distinction between recollection-based and familiarity-based retrieval processes is similarly important with respect to emotional memory retrieval. Indeed, controlled (i.e., explicit, recollection-based) and automatic (i.e., implicit, familiarity-based) retrieval processes may differentially recruit attention to guide memory search and retrieval.

To test this hypothesis, one study examined the role of attention bias toward positive stimuli during memory retrieval in modulating positive LTM bias (Everaert \& Koster, 2015). During an encoding task, healthy unselected participants were instructed to elaborate on both positive and negative meanings from scrambled sentences to select the most self-descriptive sentence (e.g., "I am a born loser" and "I am a born winner" derived from "born winner am loser a I"). After a 
retention interval, participants were instructed to search their memory for the sentences they had selected in response to pairs of retrieval cues including a negative and positive word cue (e.g., winner vs. loser). One cue was linked to the target memory (e.g., "I am a born winner") and the other to the distractor memory (e.g., "I am a born loser"). Recollection- and familiarity-based retrieval processes during recognition were distinguished using a Remember-Know procedure (Tulving, 1985). This procedure requires participants to decide whether their retrieval of the sentences was based on 'remembering' (i.e., recollection-based: details of the sentence were recalled) or 'knowing' (i.e., familiarity-based: a feeling that an item was previously encountered without much detail). Eye movements were registered during memory search to measure attention biases toward positive vs. negative retrieval cues. Biased attention toward positive information was related to greater recollection of positive compared to negative target memories. Interestingly, this relation occurred only during recollection-based retrieval (Remember responses). Attention bias during familiarity-based retrieval (Know responses) was not related to recollection of positive or negative material. These findings suggest that controlled but not automatic retrieval of emotional memories may be modulated by a positive attention bias in healthy individuals. In future research, it would be interesting to examine how depression modulates biases in these attention and memory processes. Based on cognitive and emotion research, we expect that depression-linked bias in attention may skew retrieval of emotional material during recollection-based retrieval to potentiate a negative and attenuate a positive LTM bias.

Although basic research suggests that attention primarily modulates retrieval from explicit LTM, the possibility that attention can alter implicit retrieval processes in depression cannot be ruled out. Whereas explicit LTM retrieval can be initiated by internal as well as external cues, implicit LTM retrieval may be tied to the processing of identical or related events and be associated with external attention (Kim, 2019). Basic research has shown that implicit memory retrieval 
mainly occurs via associative processes linked to situational cues (Lozito \& Mulligan, 2010). Therefore, unintentional retrieval paradigms (i.e., memory tasks that do not explicitly instruct participants to search for a target memory) may be better suited to address whether attention biases toward particular cues automatically trigger emotional memories (e.g., Barzykowski \& Staugaard, 2016). With respect to depression, research could test whether attention bias guides the activation of negative representations from implicit memory by studying negative intrusive memories. Prior work has shown that depression is characterized by involuntary intrusive negative autobiographical memories (Newby, Lang, Werner-Seidler, Holmes, \& Moulds, 2014; Reynolds \& Brewin, 1999) and impaired positive autobiographical memory (Begovic et al., 2017). Analogous to posttraumatic memory intrusions (Schäfer, Zvielli, Höfler, Wittchen, \& Bernstein, 2018), it possible that a depression-linked attention bias toward negative situational cues is related to more intrusions of negative autobiographical memories and an attenuated positive attention bias is related to fewer intrusions of positive autobiographical memories.

\subsection{LTM bias guides the allocation of attention}

Memories derived from prior experiences support the processing of incoming information, providing predictive information about which aspects of a situation are likely to be relevant (Dudukovic \& Wagner, 2006). LTM representations can be recruited to guide the allocation of selective attention and facilitate perception of relevant stimuli. The deployment of attention is expected to be influenced by both implicit and explicit memory systems (Hasson et al., 2015; Hutchinson \& Turk-Browne, 2012; Todd \& Manaligod, 2017).

One way in which prior learning may bias the allocation of attention is via implicit LTM. Most studies testing this hypothesis involve an associative learning phase followed by an attention task. The learning phase typically involves repeated pairings of neutral stimuli and emotional outcomes while participants execute a cover task. The attention task subsequently presents only 
the neutral stimuli to examine whether the learned associations with emotional content capture attention. In healthy individuals, studies have shown that associative learning of stable relations between a neutral stimulus (e.g., a shape or color) and aversive events (Anderson \& Britton, 2019; Koster et al., 2004; Schmidt, Belopolsky, \& Theeuwes, 2015) or reward (Chelazzi, Perlato, Santandrea, \& Della Libera, 2013; Hickey \& van Zoest, 2013) involuntary guides attention selection toward matching stimuli. For example, one study showed that task-irrelevant stimuli that were previously associated with reward involuntarily capture attention and disrupt visual search for a salient target (Anderson, Laurent, \& Yantis, 2011). Moreover, the reward history of a stimulus may have a lasting effect on the deployment of attention, such that it may be observed several days after the end of the learning phase (Della Libera \& Chelazzi, 2009).

In the context of depression, two studies have examined how prior learning modulates attention allocation. In one study (Anderson, Leal, Hall, Yassa, \& Yantis, 2014), adults low vs. high in depression symptoms completed a learning phase including a visual search task in which they searched for color-defined targets. Participants received monetary reward when the targets were correctly reported. Subsequently, during the test phase, participants completed another visual search task. In this task, the target was defined by shape (e.g., a square among circles) while color was irrelevant to the task. On a subset of trials during the test phase, one of the non-targets was presented in the color of a previously reward-associated target. Attention was captured by rewardrelated stimuli in those low but not high in depression (Anderson et al., 2014). These observations suggest that depression may be associated with a relatively blunted influence of prior reward on attention selection.

Similar observations were reported in a second study examining how reward and punishment learning modulate attention allocation in adults low vs. high in depression symptoms (Brailean, Koster, Hoorelbeke, \& De Raedt, 2014). Participants first completed a learning phase in 
which shapes were paired with monetary gains or losses. The subsequent test phase involved a dot probe task presenting the shapes signaling reward or loss. Similar to Anderson et al (2014), those low in depression levels oriented attention toward reward-associated stimuli whereas individuals with higher depression levels do not orient attention toward stimuli associated with reward (Brailean et al., 2014). In contrast, there were no differences between low and high depression with respect to attention biases toward stimuli signaling loss. The results of these two studies suggest that the reward learning history of a stimulus modifies its attentional priority and that depression modulates how associative learning guides attention allocation.

Explicit LTM systems may also contribute to biased allocation of attention to emotional information. Studies have shown that explicit LTM representations influence different operations of attention (Becker \& Rasmussen, 2008; Kruijne \& Meeter, 2016; Summerfield, Rao, Garside, \& Nobre, 2011). For example, one study examined how memory may be leveraged to find a target in complex visual scenes (Summerfield, Lepsien, Gitelman, Mesulam, \& Nobre, 2006). In this study, participants were familiarized with a set of complex visual scenes, several of which contained a target object. Next, participants completed a cued visual orienting task and a memory-orienting task. In the cued visual-orienting task, participants detected whether a cued target object was present within novel scenes. In the memory-orienting task, participants detected whether a cued target was present within the familiar scenes. Participants were significantly faster at detecting the target object within familiar vs. novel scenes, indicating that memories can be used to guide attention to a target's expected location in complex visual scenes (Summerfield et al., 2006). A recent study modified a similar paradigm to study whether punishment-related memories likewise drive attention allocation (Suárez-Suárez, Rodríguez Holguín, Cadaveira, Nobre, \& Doallo, 2019). Contextual memories paired with punishment avoidance led to faster responses to targets presented at remembered locations. Applying these observations to depression, it seems likely that greater 
accessibility of negative memories stored in explicit LTM (Joormann \& Siemer, 2004) may increase the likelihood that these memories are used to guide attention allocation when searching for relevant information.

\subsection{Working memory difficulties modulate attention bias - LTM bias interactions}

WM is closely interconnected with attention and LTM processes (for a comprehensive review, see Fougnie, 2008). Studies have repeatedly shown that the contents of WM may guide attention toward matching external stimuli and that, in turn, attention selects which stimuli are stored in WM (Awh et al., 2006; Luck \& Gold, 2008; Soto, Hodsoll, Rotshtein, \& Humphreys, 2008). The information that is held online in WM can be used to direct attention toward relevant mental representations when searching for targets in LTM, which are then represented in WM once activated (Kizilirmak, Rösler, \& Khader, 2012; Polyn \& Kahana, 2008). In this way, WM serves as an interface between external attention and LTM (Chun et al., 2011). It is therefore plausible that executive control operations, which regulate the contents of WM, modulate the interactions between biases of attention and LTM.

Executive control operations are theorized to cause difficulties to disengage attention from processing negative information in depression (Joormann, 2010; Koster et al., 2011). Difficulties in inhibitory control of irrelevant negative information in WM may cause attention to be focused on negative instead of positive information, which may facilitate processing of attended information and inhibition of processing for the relatively less attended (e.g., positive) information. By selecting matching items from external (e.g., environmental stimuli) or internal (e.g., items retrieved from LTM) sources, this negative attention bias may fuel the negative contents that are stored in WM (and maintained through difficulties in shifting and updating of WM representations). This process may produce differential processing of selected (i.e., negative) and unselected (e.g., positive) information, and influence which information is encoded into LTM and set the stage for 
LTM biases. Thus, by guiding both external and internal attention, difficulties in executive control operations may affect the mutual influences that occur between attention and LTM biases.

In depression, difficulties in executive control operations have been linked to attention and memory biases. One recent study in a nonclinical sample tested whether executive control difficulties over emotional material predicted self-reported depressive symptoms through cognitive biases (Everaert, Grahek, \& Koster, 2017). Individuals varying in depression levels completed several executive control tasks measuring difficulties in inhibition, shifting, and updating when processing emotional information as well as an attention bias task while processing self-relevant sentences. Negative attention bias was specifically related to difficulties in inhibiting negative material from WM. Difficulties in WM updating and shifting between negative and positive mental representations were not related to attention bias, but were related to a bias in negative vs. positive self-related sentences that were constructed during the attention bias task. Further support for relations between WM difficulties and cognitive biases comes from a study in which WM was trained healthy individuals using a variant of the emotional n-back task. This study found that the WM training led to improved attentional control over emotional stimuli on an emotional Stroop task (Schweizer, Hampshire, \& Dalgleish, 2011). This finding suggests that WM operations have a causal influence on attention bias. Finally, a recent study reported evidence supporting the role of WM operations in regulating LTM biases. In this study, individuals with a tendency to engage in repetitive negative thinking were trained to inhibit negative material from WM (Daches, Mor, \& Hertel, 2019). Examining effects on LTM, it was found that the training resulted in a less negative bias in LTM. This is consistent with the hypothesis that WM operations causally influence LTM biases.

Collectively, these initial research findings suggest that WM operations and biases in both attention and memory are closely associated. Current evidence is in line with the notion that 
working memory operations mediate interactions between biases in attention and LTM. Next, research is needed to investigate WM difficulties in relation to attention and memory biases concurrently. This may be particularly instructive in better understanding the putative functions(s) of WM in the interactions between attention and LTM biases.

\subsection{Summary}

Current research findings are consistent with the notion that cognitive biases are not isolated but interrelated processes. There is evidence suggesting that (a) depression-linked attention biases during encoding modulate the contents of explicit and implicit LTM; (b) positive attention bias modulates controlled but not automatic retrieval of emotional memories in healthy individuals; (c) depression is linked to a blunted influence of prior reward learning on attention selection; and (d) executive control difficulties are related to both attention and memory biases in depression. However, it should be noted that the strength of the relations between attention biases, WM difficulties, and LTM biases is within the small to moderate range (i.e., $r$ 's between .20 and .60). This suggests that other factors may modulate the strength of their mutual influences, potentiating or disrupting the vicious cycles of biased processing of emotional information. Additional research is needed to elucidate how various factors such as goal formulation (Mogg \& Bradley, 2018), goal relevance appraisals (Kolnes, Naar, Allik, \& Uusberg, 2019), stress levels (Quinn \& Joormann, 2015), and resilience (Hoorelbeke, Van den Bergh, Wichers, \& Koster, 2019) may influence the manifestation of cognitive biases and their interactions in depression across time and contexts.

\section{Dynamic features of attention and memory bias interactions in depression}

Attention and memory have long been conceptualized as dynamic processes with mutually reinforcing influences (Neisser, 1967). This basic property of attention and memory likely applies to cognitive biases. As depicted in Figure 1, negative memory representations that are stored in explicit and implicit LTM may both orient and maintain attention on congruent material in the 
environment that matches the content of the memories. The resulting negative bias in attention may in turn enhance processing of negative material and attenuate processing of positive information, as such improving encoding of negative material into WM and LTM. This may further consolidate initial negative memory representations, thereby potentiating their ability to guide attention toward congruent information, etc. Indeed, investigators have argued that attention biases, working memory difficulties, and LTM biases may instigate pathogenic cycles of increasingly negative and less positive information-processing through their bidirectional influences (Wittenborn et al., 2016). Cognitive biases may then not operate in a stable trait-like manner, but rather fluctuate over time and contexts (Everaert, Bronstein, Cannon, \& Joormann, 2018; Quinn \& Joormann, 2015; Reinhart, McClenahan, \& Woodman, 2016; Zvielli, Bernstein, \& Koster, 2014). This implies that the strength of the mutual influences between cognitive biases may also vary over time. To study fluctuations in the interplay among cognitive biases, attention and memory processes (and their interactions) could be modeled in time, from seconds to minutes to hours to days, and even across developmental phases spanning years.

Dynamic conceptualizations of attention and memory are gaining renewed interest in basic cognitive science (Aben, Verguts, \& Van den Bussche, 2017; deBettencourt, Keene, Awh, \& Vogel, 2019; Stokes \& Spaak, 2016) and are emerging in research on depression. With respect to attention bias, computational approaches have been proposed to quantify attention bias as a dynamic process that fluctuates toward and away from motivationally relevant stimuli (Iacoviello et al., 2014; Zvielli et al., 2014). These data analytic strategies propose parameters such as phasic bursts and temporal variability of attention bias. The parameters are extracted from standard attention task data by serial ordering of the repeated expression of attention bias among successive observations at the triallevel. Employing such dynamic parameters, studies are starting to characterize the dynamic nature of attention bias. For example, current research suggests that remitted depression is characterized 
by greater variability in attention bias (Zvielli et al., 2016). Importantly, dynamic indices of attention bias outperform the traditional static indices with regard to psychometric properties and the prediction of psychopathology (Davis et al., 2016; Yuval, Zvielli, \& Bernstein, 2017; Zvielli et al., 2014, 2016). Yet, further research may be needed to optimize current computational methods (Kruijt et al., 2016; Zvielli et al., 2016). In particular, studies are needed that distinguish sources of variability in response time and eye movements (I. Amir, Zvielli, \& Bernstein, 2016). Additionally, novel paradigms are needed that are designed a priori to measure and quantify attention bias as a dynamic process (Zvielli et al., 2014, 2016).

More dynamic conceptualizations of memory bias also merit investigation. Memories are dynamic entities that change over time through processes of formation, consolidation, and reconsolidation. Capturing how emotional memories are organized in LTM seems important to gain insight into dynamic aspects of negative and positive emotional memories. However, research traditionally considers the number of accurately remembered negative, positive, and neutral items to calculate bias indexes reflecting the proportion of negative items. Such aggregated scores ignore the serial order in which items are recalled from memory, which could reveal their clustering and organization in LTM (Polyn \& Kahana, 2008; Polyn, Norman, \& Kahana, 2009). Indexes based on the serial position of item recall may be useful to characterize dynamic properties of LTM biases in emotional disorders. For example, the strength of associations between memories could be quantified by calculating the probability of continued recall of negative vs. positive items (van Vugt, Hitchcock, Shahar, \& Britton, 2012). This index considers the number of items of the same emotion category that are recalled successively as well as transitions from recalling items of one category to another. Interestingly, a previous study in individuals with recurrent depression has shown that mindfulness decreased the probability of continued negative memory recall and increased continued positive memory recall (van Vugt et al., 2012). This study suggests that 
considering the patterns of memory retrieval may cast light on dynamic properties of memory biases, such as the persistence of recalling negative information.

Time-sensitive indices of attention and memory biases may help to address outstanding questions regarding the dynamic nature of their interactions at micro and macro timescales. For example, at a micro timescale, it remains puzzling why people recall only a subset of emotional memories while they have attended to different kinds of emotional information. Fluctuations in attention bias over time may help account for intra-individual variability in the performance on emotional memory tasks. Consistent with this idea, basic research has shown that attention lapses lead to worse memory performance (deBettencourt et al., 2019). Applied to cognitive processing of emotional information, peaks or bursts in the phasic expression in attention bias may explain which material is prioritized for encoding in WM and thereby result in better LTM for the attended items as well as those items that are semantically related.

Moreover, at a macro timescale, it has yet to be investigated whether interactions among cognitive biases are changed by developmental maturation processes. Current evidence suggests that depression-linked attention biases may already emerge from an early age (Lau \& Waters, 2017; Platt, Waters, Schulte-Koerne, Engelmann, \& Salemink, 2017) and that LTM biases in depression may be more characteristic for adolescents than for children with depression (Lau \& Waters, 2017). Such fluctuations in the nature of cognitive biases may then determine which interactions among these processes plausibly occur. To-date, one study examined correlations between cognitive biases in adolescents suffering from clinical depression. This study observed that recall of positive words was negatively correlated with a congruent bias in the higher-order cognitive process of interpretation (Orchard \& Reynolds, 2018). This finding suggests that attention and memory processes may interact during adolescence. Yet, follow-up research is required to explicitly model specific interactions between these cognitive biases in adolescence. In studying the role of 
maturation processes on cognitive processing of emotional information, it seems important to examine the temporal stability of cognitive biases across development. Such research efforts may provide insight into whether these processes and their interactions represent enduring risk for depression (e.g., Hankin, 2008).

In sum, understanding the fluctuations of cognitive biases may provide critical knowledge to accurately conceptualize the (dynamic) nature of these processes in depression. In addition, this work is important to gain insight into the contexts and periods of life during which attention and memory biases more intimately interact, and increase risk to developing depression.

\section{Methodological considerations and recommendations}

Different methodological approaches have been employed to study relations between cognitive biases in depression. One approach involves combining experimental paradigms measuring different cognitive biases during a single study session. For example, studies have combined attention bias tasks (e.g., emotional dot probe task, emotional Stroop task) with a selfreferential encoding task and subsequent free recall test to investigate whether attention and LTM biases are correlated (for examples, see Gotlib et al., 2004; Sanchez, Duque, Romero, \& Vazquez, 2017; Vrijsen, Van Oostrom, Isaac, Becker, \& Speckens, 2014). In this approach, experimental paradigms are independent and present unique stimulus materials. Such studies usefully determine whether biases occur in multiple related cognitive processes independently, but cannot provide insight into their specific interactions. A different approach may be indicated if we hope to develop more fine-grained understanding of how attention bias influences memory biases and vice versa.

To this end, researchers have adopted another approach in which multiple experimental tasks are combined and modified to present the same stimulus materials. Experimental tasks are administered in a fixed temporal order to examine how one bias (e.g., during encoding or retrieval) is related to later processing of the same stimulus materials. The designed dependency in terms of 
shared stimuli and temporal order allows these studies to address questions related to specific attention-memory bias interactions in an experimental context. As extensively discussed earlier in this article, this type of study design has been commonly applied in basic sciences as well as clinical studies to investigate how attention biases regulate emotional memory and vice versa in depression.

Whereas this second methodological approach allows some confidence in the direction of effects, direct proof of causality requires experimental manipulation of one cognitive process to track effects on other process. Therefore, in a third approach, studies have utilized cognitive training methods to manipulate cognitive biases and examine transfer of training to other processes. At present, most studies have attempted to determine the causal role of attention bias. For example, one study trained participants to orient attention away from negative words using a training variant of the dot-probe task (Blaut, Paulewicz, Szastok, Prochwicz, \& Koster, 2013). A subsequent memory test measured the impact of the training on LTM processes. As we will discuss below, there are increasing concerns about the effectiveness of certain cognitive training procedures (e.g., dot probe training task; Koster \& Bernstein, 2015). Unsuccessful implementation of training paradigms limits the ability to draw firm conclusions regarding the sources of potential transfer of training effects. Therefore, we recommend that future work capitalizes on recent innovations in attention training (e.g., Bernstein \& Zvielli, 2014; Lazarov, Pine, \& Bar-Haim, 2017; Sanchez, Everaert, \& Koster, 2016; Schnyer et al., 2015) to test the hypothesized influence of attention bias on other cognitive processes. Moreover, novel procedures to modify memory bias enable researchers to investigate how this bias influences attention allocation (Hertel, Maydon, Cottle, \& Vrijsen, 2017; Vrijsen, Hertel, \& Becker, 2016).

In reviewing approaches to study attention-memory bias interactions in depression, it becomes clear that most studies have employed behavioral paradigms. Though studies have identified abnormalities at the neural system level that contribute to biased information-processing 
in depression (for reviews, see De Raedt \& Koster, 2010; Disner, Beevers, Haigh, \& Beck, 2011), the neural underpinnings of interactions among attention and memory biases remain unclear. Research from cognitive (Chun \& Turk-Browne, 2007) and affective (Dolcos et al., 2019) science, as well as recent work on anxiety (e.g., Aue \& Okon-Singer, 2015), has already successfully employed brain imaging methods such as functional magnetic resonance imaging, neurostimulation techniques, and event-related potentials to study interactions between cognitive biases at the neural level. Future research on depression may capitalize on this innovative work and combine behavioral paradigms and brain-imaging methods to formulate an integrated understanding of attention-memory bias interactions.

On a final note, the reliability of experimental tasks measuring cognitive biases has become the focus of increasing concern (McNally, 2019; Rodebaugh et al., 2016). Studies that have investigated psychometric properties of the emotional dot probe task have reported low split-half and test-retest reliabilities (Schmukle, 2005; Waechter, Nelson, Wright, Hyatt, \& Oakman, 2014). While not all attention bias tasks may possess poor psychometric properties (Sears, Quigley, Fernandez, Newman, \& Dobson, 2018) and novel dynamic attention bias parameters may be more reliable (Iacoviello et al., 2014; Zvielli et al., 2014), the reliability and validity of many cognitive tasks is unknown. The absence of (knowledge about) reliable bias indexes may jeopardize systematic progress in integrative research on cognitive mechanisms in depression. In moving forward, future research on attention-memory bias interactions in depression may benefit from the development (and validation) of novel research paradigms that are specifically designed to capture specific features of attention-memory bias interactions. Experimental paradigms that have been successfully employed in basic cognitive and emotion science may usefully guide this method development effort in clinical science. 


\section{Future directions}

This article reviewed extant research on interactions among attention biases, WM difficulties, and LTM biases in depression to elucidate promising mechanisms implicated in this disorder. However, despite emerging research, it is clear that important gaps in our knowledge remain. Throughout the article, we highlighted specific directions for empirical research in this area to more realistically capture the multifactorial interactions among cognitive biases in depression. In this section, we outline broader directions for the field to better understand how cognitive biases translate to depression, advance current cognitive training interventions for depression, and establish transdiagnostic properties of attention-memory bias interactions.

\subsection{Uncovering how attention-memory bias translate to depression}

Attention and memory biases represent lower-level cognitive processes that may be more proximally linked to higher-level pathogenic processes implicated in the onset, maintenance, and relapse of depressive symptoms. That is, mutually reinforcing attention and memory biases may derail higher-order processes such as the interpretation of ambiguity as well as emotion reactivity and regulation, thereby contributing to the development of depressive symptoms. Below, we illustrate how attention-memory bias interactions could distort these higher-order processes and set the stage for psychological maladaptation.

\subsubsection{Interpretation biases}

Depression has been associated with a tendency to draw more negative and fewer positive interpretations to account for ambiguous emotional information (Everaert, Podina, \& Koster, 2017; Wisco, 2009). Interpretation is a semantic process that involves integration of different aspects of a situation to construct mental representations that resolve ambiguity (Hirsch, Meeten, Krahé, \& Reeder, 2016). This process of ambiguity resolution relies on a set of cognitive operations that subserve the generation of multiple explanations followed by the selection of an explanation that 
is most applicable to a situation (Huppert, Pasupuleti, Foa, \& Mathews, 2007). In depression, both the generation and selection of possible interpretations may be biased with more negative vs. positive interpretations that are generated upon encountering ambiguity as well as more negative vs. positive interpretations that are selected as most plausible (Wisco, 2009). Biases in basic cognitive processes and their interactions may lie at the core of the skewed generation and selection of emotional interpretations, as such influencing how people suffering from depression make sense of ambiguous emotional experiences.

In interpreting ambiguous situations (e.g., someone in the audience frowns while you are giving a presentation), it is plausible that the generation of interpretations is guided by prior knowledge and/or experiences in similar situations (i.e., cognitive schema). These autobiographical memories could be consciously retrieved or automatically triggered from LTM by allocating attention toward cues in the environment. A negative attention bias and attenuated positive attention bias (e.g., looking at someone yawning and not at a smiling attendee) may make more negative than positive long-term memories accessible (e.g., previous presentations or speeches that did not went well), thereby setting the stage for a congruent bias in interpretation generation (e.g., "my research is not interesting", "they think I am not a good speaker", etc.). In considering generated interpretations, the different options must be held online in WM and the most plausible interpretation must be selected from its competitors. Difficulties in executive control and biases in attention likely influence this selection process. In particular, difficulties in inhibiting negative representations, shifting between negative and positive representations, and updating WM by removing irrelevant negative material may result in a disproportionate representation of negative vs. positive interpretations in WM (at the expense of the positive or neutral interpretations, e.g., "that person in the audience must be tired"). These biased WM contents may then guide attention toward matching (external) information (e.g., someone who is busy with his/her mobile phone) 
which may in turn bias what is subsequently encoded and maintained in WM (e.g., "nobody is interested in my work"). These bidirectional influences between WM and external attention bias may increase the likelihood that a negative and not a positive interpretation is selected as the most plausible explanation for that particular situation. The selected interpretation may then be encoded into LTM and hence influence what is available for later retrieval from LTM when ambiguity is encountered. This may instigate a self-maintaining cycle of increasingly negative as well as less positive information-processing, shaping one's views about the self (e.g., "I am a failure"), others (e.g., "people do not care about what I do"), and future (e.g., "my future looks dismal").

\subsubsection{Emotional responding and emotion regulation}

When exposed to psychosocial stressors (e.g., a job interview), those suffering from depression may allocate attention more to negative than positive cues (e.g., a frowning vs. a smiling interviewer). This biased allocation of attention may elicit negative emotions (e.g., sadness, anger) and prevent depressed individuals from reorienting attention to positive or rewarding cues (e.g., focusing on the other assessors) as a regulatory strategy that could reduce negative and increase positive emotions. It is then more likely that more negative than positive information enters WM. This skewed processing of emotional information in WM may be maintained through a bias in attention modulation and executive control difficulties, which may both fuel negative and dampen positive thoughts (e.g., "I am making a bad impression", "things will go wrong") as well as guide attention toward matching information in the environment. This cycle of attention bias fueling negative content in WM and WM guiding attention toward congruent information may then hamper reappraisal of the stressful situation in a more positive manner and increase repetitive negative thinking (e.g., "I will never get a job"). These attention bias - WM interactions may then fucntion to maintain one's negative emotional response to the stressful event, dampen any positive emotions (e.g., excitement), and impair emotional recovery from the stressor. Moreover, the negative 
information that is maintained in WM may guide retrieval of memories of related emotional experiences from LTM (e.g., "last time I also performed badly during an interview, hence I'm a loser"). These memories may further intensify the emotional stress response (i.e., the negative emotions), guide attention toward other negative cues (e.g., signs of rejection), and reinforce negative WM contents. As a result, more negative than positive meanings may be encoded into LTM and strengthen memory biases. This biased encoding of negative information may jeopardize the use of mood-incongruent recall of positive or rewarding memories to repair negative mood in the future, which may be further compromised by attention biases during memory retrieval.

While short-term negative processing biases in attention and memory may serve to effectively process and manage stressors (Albert \& Newhouse, 2019), strong mutual influences between attention and memory biases (rather than individual biases) in response to stressors may help to explain when these cognitive processes become persistent and inflexible, contribute to prolonged emotional dysregulation, and the development of hallmark depression symptoms (e.g., sustained negative mood, loss of pleasure). Prior research has already shown that biases in individual cognitive processes are related to increased emotional responding to stress (Ellenbogen et al., 2002), diminished recovery from stress (Clasen et al., 2013; Sanchez et al., 2013), and emotion regulation difficulties such as infrequent use of reappraisal and frequent repetitive negative thinking (for a review, see Joormann \& Vanderlind, 2014). Yet, studies have yet to uncover how the interactions among cognitive processes are implicated in emotional responding and emotion regulation in depression. Moving toward a higher level of specificity regarding emotional states, this work would further benefit from distinguishing discrete positive (e.g., happiness, hope, pride) and negative (e.g., sadness, anger, guilt) emotions to consider how interacting cognitive processes may influence (networks of) interrelated discrete emotions (e.g., Pe et al., 2015). As illustrated in this section, the four mechanisms of attention and memory bias interactions could guide this 
endeavor to better understand the cognitive mechanisms involved in emotional dysregulation in depression.

\subsection{Advancing cognitive training interventions}

Identifying the interactions among biases in attention, WM, and LTM in depression may provide important clues for cognitive training interventions targeting psychopathology risk processes. Cognitive training interventions have attracted considerable attention as a potential tool to reduce the burden associated with depression and other mental disorders (Hertel \& Mathews, 2011; MacLeod \& Mathews, 2012). These methods have adapted existing cognitive paradigms to expose trainees to contingencies between emotional stimuli and target responses in a way that encourages attenuation of a targeted bias in cognition. Various procedures have been developed to target biases in attention or memory processes. However, meta-analyses suggest that current training methods yield, at best, small and temporary effects on depressive symptomatology (Cristea, Kok, \& Cuijpers, 2015; Hallion \& Ruscio, 2011; Koster, Hoorelbeke, Onraedt, Owens, \& Derakshan, 2017). This clearly indicates that there is room for improvement.

\subsubsection{How to target biased cognitive processes?}

Despite advances in integrative research on cognitive biases in depression, cognitive training studies have typically targeted single cognitive processes (e.g., attention bias through a dot probe training protocol) and disregarded (potential) mutual influences that may occur among them. Yet, research on attention-memory bias interactions may inform how to disrupt the interlocking vicious cycles and improve cognitive training approaches to obtain therapeutic effects. To disrupt a cascade of cognitive biases, one could target attention biases through training to effect change in the type of emotional information that is held online in WM and encoded into LTM (Blaut et al., 2013). While this approach of focusing on a single cognitive process to disrupt the whole system seems promising, current research has repeatedly failed to find such transfer of training to other 
cognitive processes in depression (Bowler et al., 2017; Everaert, Mogoaşe, David, \& Koster, 2015; LeMoult et al., 2017; Voogd, Wiers, \& Salemink, 2017). A lack of transfer of attention bias training to other cognitive processes (e.g., emotional interpretations and LTM) seems particularly problematic because the unaffected cognitive processes could in turn guide attention away from stimuli with positive or rewarding associations and toward negative stimuli in the environment. This may then reduce any beneficial effects obtained through attention bias training. Thus, employing paradigms that target cognitive processes directly and exclusively may not be sufficient to ameliorate other cognitive risk processes in depression.

To efficiently reduce cognitive risk for depression, integrative cognitive training paradigms may be needed to target basic cognitive processes in contexts when they interact with or operate as part of other (higher-order) cognitive risk processes. The development of such integrative cognitive training paradigms may capitalize on innovations in research on attention-memory bias interactions. For example, recent work utilized a paradigm for examining the interplay among biases of attention, memory, and higher-order processes of interpretation in depression (Everaert et al., 2014). The paradigm was modified into a training variant in which negative attention bias was targeted through gaze-contingent feedback while participants elaborated on positive self-referent interpretations (Sanchez et al., 2016; Sanchez, Everaert, van Put, De Raedt, \& Koster, 2019). During training, participants were instructed to allocate attention toward positive words of scrambled sentences (e.g., born winner am loser a I) to efficiently construct positive meanings using five of the six displayed words. Participants were provided with personalized eye gaze-contingent feedback to increase awareness of attention allocation and promote self-regulatory control as well as goal-directed shifting (see also Bernstein \& Zvielli, 2014; Ruimi et al., 2018). In this way, the training procedure targets reallocation of attention to create interpretations that are more positive (and may influence emotional LTM, see Everaert et al., 2014). This integrated training approach aims to modify 
attention biases and higher-order mental representations (interpretations), as well as how one bias influences the other (i.e., reallocating attention to create more benign interpretations). The results of three studies showed that the training successfully induced a positive attention bias, enhanced positive reappraisal of negative scenes, and reduced rumination as reflected by the performance on the transfer of training tasks (Sanchez-Lopez, De Raedt, van Put, \& Koster, 2019; Sanchez et al., 2016, 2019). Thus, paradigms utilized to study interactive cognitive processes can be usefully applied to develop a new next generation of cognitive training methods that directly impact higherlevel cognitive risk processes.

\subsubsection{When to target biased cognitive processes?}

Besides questions relating to how cognitive biases should be targeted, another set of questions pertains to when these processes and their interactions should be targeted. In this respect, investigators increasingly emphasize that processing biases toward negative or positive information may not be consistently (mal)adaptive (Everaert et al., 2018; Mehu \& Scherer, 2015). For example, even biased negative interpretations may motivate people to adjust their behavior to meet situational demands. Consistently drawing positive interpretations may lead people to ignore important negative features of situations, such as problems at work or difficulties in romantic relationships. Whether negative or positive biases in cognitive processes promote (mal)adaptive behavior may hinge on the fluctuating demands of the context in which these processes operate (Everaert et al., 2018; Kashdan \& Rottenberg, 2010; Mehu \& Scherer, 2015; Stange, Alloy, \& Fresco, 2017). That is, the inflexible nature of cognitive processes may cause a mismatch between the process and changing situational demands, thereby increasing risk for depression. Providing support for this notion, research has shown that depression is characterized by rigid responses to the environment in a number of processes such as WM operations (Joormann, 2010; Koster et al., 2011), emotional responding (Bylsma, Morris, \& Rottenberg, 2008; Houben, Van Den Noortgate, 
\& Kuppens, 2015), and emotion regulation (Joormann \& Vanderlind, 2014). Emerging research suggests that depression is also marked by inflexibility in revising initial negative interpretations and expectations in the face of disconfirmatory positive information (Everaert et al., 2018; Kube, Rief, Gollwitzer, Gärtner, \& Glombiewski, 2018). This novel work suggests that cognitive training interventions may need to focus on facilitating context-dependent flexibility in attention and memory processes rather than inducing an overall positive bias and/or reducing a negative bias to promote adaptive responding.

Identifying contexts that may elicit inflexible responses and implementing training paradigms within such contexts to facilitate the intake of disconfirmatory information represent important avenues for future research. In this respect, recent developments in terms of dynamic conceptualizations (Everaert et al., 2018; van Vugt et al., 2012; Zvielli et al., 2014) and novel integrative paradigms of cognitive biases (Sanchez-Lopez et al., 2019) enable investigators to collect intensive longitudinal data about these processes as depressed individuals go about their daily lives. Obtaining such ecologically valid data may help to identify the contexts under which attention and memory processes are particularly interconnected and harmful for an individual (e.g., triggers of negative repetitive thoughts, appraisals of uncontrollability, etc.). Building on such idiographic data, it will be possible to adjust the integrative cognitive training intervention to provide the right type/amount, at the right time, by adapting to an individual's changing internal and contextual state (Lei, Nahum-Shani, Lynch, Oslin, \& Murphy, 2012; Nahum-Shani et al., 2018). Of note, the importance of considering idiographic cognitive profiles with multiple cognitive processes was recently highlighted by a study showing that the best marker of future increases in depressive symptoms may be the cognitive process that is dominantly biased toward negative material (Everaert, Duyck, \& Koster, 2015). By adopting an integrative and idiographic approach to assessment and training, treatments may be able to disrupt the vicious cycles of negatively biased 
information-processing and increasing negative affect. Indeed, the four mechanisms outlined in this article can be usefully applied in guiding a personalized assessment and implementation of training methods to facilitate flexible processing of emotional information.

\subsection{Establishing transdiagnostic properties of attention-memory bias interactions}

A large body of research has provided evidence for biases in attention and/or memory across a wide range of mental disorders (for reviews and meta-analyses, see Brooks, Prince, Stahl, Campbell, \& Treasure, 2011; Eysenck, Derakshan, Santos, \& Calvo, 2007; Field, Munafò, \& Franken, 2009; Lazarov et al., 2019; Mitte, 2008; Morrison \& Heimberg, 2013; Savulich, Shergill, $\&$ Yiend, 2012). Attention and memory biases are then often viewed as transdiagnostic processes that cut across various disorders. While biases in these cognitive processes may have transdiagnostic properties, it has yet to be discovered to what extent the mechanisms of attentionmemory bias interactions generalize across mental disorders.

Theorists have hypothesized that cognitive biases interact with and exacerbate each other in various conditions including depression (Beck \& Haigh, 2014; Holmes, Lang, \& Deeprose, 2009; Wittenborn et al., 2016), anxiety disorders (Hirsch et al., 2006; Ouimet, Gawronski, \& Dozois, 2009; Peschard \& Philippot, 2016), chronic pain (Van Ryckeghem \& Vervoort, 2016), aggressive behaviors (Schippell, Vasey, Cravens-Brown, \& Bretveld, 2003), and body dissatisfaction (Jiang \& Vartanian, 2012). Indeed, it is plausible that the four mechanisms of interactions among attention and memory processes operate in various mental disorders because they reflect normal interactions among basic cognitive processes, which become biased as a disorder develops. Empirical evidence provides some support for this idea. For example, research has indicated that disorder-congruent attention biases shape one's expectancies of threat in phobic individuals (Aue \& Okon-Singer, 2015), are related to hostile interpretation biases (Schippell et al., 2003), and predict improved recognition of body-related stimuli in restrained and unrestrained eaters (Jiang \& Vartanian, 2012). 
Furthermore, interpretation biases may influence attention allocation toward threat in socially anxious individuals (N. Amir, Bomyea, \& Beard, 2010) and interpretation biases regulate the content of emotional LTM in generalized social phobia (Hertel, Brozovich, Joormann, \& Gotlib, 2008). Together, research suggests that cognitive biases may interact in several mental disorders.

Yet, differences between mental disorders in terms of the proposed attention-memory bias interactions may arise depending on the nature of biased cognitive processes characteristic of a particular disorder. For example, whereas depression involves biases in both implicit and explicit LTM processes (Gaddy \& Ingram, 2014; Matt et al., 1992), anxiety is related to enhanced recall of threat-related information but not to biases in explicit recognition or implicit memory tasks (Mitte, 2008). Such distinctive features regarding the nature of cognitive biases may determine which mechanisms of attention-memory bias interactions can be plausibly expected in a disorder. Using the previous example, it is less likely that implicit LTM processes will systematically bias the allocation of attention in anxiety because this condition does not involve implicit LTM biases. In researching attention-memory bias interactions within specific mental disorders, it is important to consider the presence of comorbid mental disorders. Exploring the role of comorbid depression, one study observed that attention bias predicted subsequent recognition memory only in participants with social anxiety disorder and comorbid depression (LeMoult \& Joormann, 2012). Attention and memory biases were not related in the group of individuals with social anxiety disorder. These findings suggest that comorbid psychopathology influences the manifestation of biases in attention and memory as well as their interactions.

In moving this research forward, investigations of biased cognitive processes and their interactions could draw on advances in the conceptualization of mental disorders. While traditional approaches consider risk factors at the disorder level, novel approaches such as the Research Domain Criteria (RDoC; Sanislow et al., 2010), expanded network models (Borsboom, 2017), and 
the Hierarchical Taxonomy of Psychopathology (HiTOP; Kotov, Krueger, \& Watson, 2018) acknowledge symptomatic heterogeneity within disorders and unclear boundaries between mental disorders. This is particularly important because clinically different symptoms (e.g., sad mood vs. insomnia) characterizing one or multiple disorders may be differentially related to biases in cognitive processes. Adopting a symptom-level focus, recent work has shown that a negative memory bias, and not attention bias, is related to individual depression symptoms such as negative mood, worthlessness, feelings of failure, and pessimism (Beevers et al., 2019; Marchetti et al., 2018). In a sample of individuals with social anxiety disorder, another study found that attention modulation bias toward threat cues was related to both fear and avoidance of social situations (Heeren \& McNally, 2016). Further research could build on this seminal work and examine whether multiple interacting cognitive processes are differentially related to individual symptoms and 'bridge' symptom clusters of various mental disorders (for an example, see Everaert \& Joormann, 2019). In this way, research may uncover complex relations among symptoms of mental disorders and cognitive biases, casting light on pathways through which these processes operate within and across mental disorders.

\section{Conclusion}

Uncovering the complex interactions among attention biases, working memory difficulties, and long-term memory biases may be important to understanding cognitive foundations of mental disorders broadly and depression specifically. We proposed four mechanisms through which attention and memory processes may interact in depression. We hope that this article may help consolidate and synthesize extant research to-date as well as serve as a starting point for a new phase of research on complex dynamic systems of cognitive processes that advances theories and treatments to reduce the burden of depression and related mental disorders. 


\section{Acknowledgements}

The authors thank Alexandre Heeren, Matt R. Judah, and Andrew Peckham for their feedback on early versions of this manuscript. Preparation of this article was supported by grants from the Belgian American Educational Foundation, the Special Research Fund at Ghent University, a postdoctoral fellowship from the Research Foundation - Flanders awarded to Jonas Everaert, a concerted research action grant of Ghent University (BOF16/GOA/017) awarded to Ernst Koster, and from the Israel Science Foundation awarded to Amit Bernstein. 


\section{References}

Aben, B., Verguts, T., \& Van den Bussche, E. (2017). Beyond trial-by-trial adaptation: A quantification of the time scale of cognitive control. Journal of Experimental Psychology: Human Perception and Performance, 43(3), 509-517. https://doi.org/10.1037/xhp0000324

Ahern, E., \& Semkovska, M. (2017). Cognitive functioning in the first-episode of major depressive disorder: A systematic review and meta-analysis. Neuropsychology, 31(1), 5272. https://doi.org/10.1037/neu0000319

Albert, K. M., \& Newhouse, P. A. (2019). Estrogen, Stress, and Depression: Cognitive and Biological Interactions. Annual Review of Clinical Psychology, 15(1), 399-423. https://doi.org/10.1146/annurev-clinpsy-050718-095557

Amir, I., Zvielli, A., \& Bernstein, A. (2016). (De)coupling of our eyes and our mind's eye: A dynamic process perspective on attentional bias. Emotion, 16(7), 978-986. https://doi.org/10.1037/emo0000172

Amir, N., Bomyea, J., \& Beard, C. (2010). The effect of single-session interpretation modification on attention bias in socially anxious individuals. Journal of Anxiety Disorders, 24(2), 178-182. https://doi.org/10.1016/j.janxdis.2009.10.005

Anderson, B. A., \& Britton, M. K. (2019). On the automaticity of attentional orienting to threatening stimuli. Emotion. https://doi.org/10.1037/emo0000596

Anderson, B. A., Laurent, P. A., \& Yantis, S. (2011). Value-driven attentional capture. Proceedings of the National Academy of Sciences, 108(25), 10367-10371. https://doi.org/10.1073/pnas.1104047108

Anderson, B. A., Leal, S. L., Hall, M. G., Yassa, M. A., \& Yantis, S. (2014). The attribution of value-based attentional priority in individuals with depressive symptoms. Cognitive, Affective, \& Behavioral Neuroscience, 14(4), 1221-1227. https://doi.org/10.3758/s13415- 
014-0301-Z

Armstrong, T., \& Olatunji, B. O. (2012). Eye tracking of attention in the affective disorders: A meta-analytic review and synthesis. Clinical Psychology Review, 32(8), 704-723. https://doi.org/10.1016/j.cpr.2012.09.004

Aue, T., \& Okon-Singer, H. (2015). Expectancy biases in fear and anxiety and their link to biases in attention. Clinical Psychology Review, 42, 83-95. https://doi.org/10.1016/j.cpr.2015.08.005

Awh, E., Vogel, E. K., \& Oh, S. H. (2006). Interactions between attention and working memory. Neuroscience, 139(1), 201-208. https://doi.org/10.1016/j.neuroscience.2005.08.023

Barzykowski, K., \& Staugaard, S. R. (2016). Does retrieval intentionality really matter? Similarities and differences between involuntary memories and directly and generatively retrieved voluntary memories. British Journal of Psychology, 107(3), 519-536. https://doi.org/10.1111/bjop.12160

Beck, A. T., \& Haigh, E. A. P. (2014). Advances in cognitive theory and therapy: The generic cognitive model. Annual Review of Clinical Psychology, 10(1), 1-24. https://doi.org/10.1146/annurev-clinpsy-032813-153734

Becker, M. W., \& Rasmussen, I. P. (2008). Guidance of attention to objects and locations by long-term memory of natural scenes. Journal of Experimental Psychology: Learning, Memory, and Cognition, 34(6), 1325-1338. https://doi.org/10.1037/a0013650

Beeney, J., \& Arnett, P. a. (2008). Stress and memory bias interact to predict depression in multiple sclerosis. Neuropsychology, 22(1), 118-126. https://doi.org/10.1037/08944105.22.1.118

Beevers, C. G., Clasen, P. C., Enock, P. M., \& Schnyer, D. M. (2015). Attention bias modification for major depressive disorder: Effects on attention bias, resting state 
connectivity, and symptom change. Journal of Abnormal Psychology, 124(3), 463-475. https://doi.org/10.1037/abn0000049

Beevers, C. G., Mullarkey, M. C., Dainer-Best, J., Stewart, R. A., Labrada, J., Allen, J. J. B., ... Shumake, J. (2019). Association between negative cognitive bias and depression: A symptom-level approach. Journal of Abnormal Psychology. https://doi.org/10.1037/abn0000405

Begovic, E., Panaite, V., Bylsma, L. M., George, C., Kovacs, M., Yaroslavsky, I., ... Rottenberg, J. (2017). Positive autobiographical memory deficits in youth with depression histories and their never-depressed siblings. British Journal of Clinical Psychology, 56(3), 329-346. https://doi.org/10.1111/bjc.12141

Bernstein, A., \& Zvielli, A. (2014). Attention Feedback Awareness and Control Training (AFACT): Experimental test of a novel intervention paradigm targeting attentional bias. Behaviour Research and Therapy, 55(1), 18-26. https://doi.org/10.1016/j.brat.2014.01.003

Blaut, A., Paulewicz, B., Szastok, M., Prochwicz, K., \& Koster, E. H. W. (2013). Are attentional bias and memory bias for negative words causally related? Journal of Behavior Therapy and Experimental Psychiatry, 44(3), 293-299. https://doi.org/10.1016/j.jbtep.2013.01.002

Borsboom, D. (2017). A network theory of mental disorders. World Psychiatry, 16(1), 5-13. https://doi.org/10.1002/wps.20375

Bowler, J. O., Hoppitt, L., Illingworth, J., Dalgleish, T., Ononaiye, M., Perez-Olivas, G., \& Mackintosh, B. (2017). Asymmetrical transfer effects of cognitive bias modification: Modifying attention to threat influences interpretation of emotional ambiguity, but not vice versa. Journal of Behavior Therapy and Experimental Psychiatry, 54, 239-246. https://doi.org/10.1016/j.jbtep.2016.08.011

Brailean, A. M., Koster, E. H. W., Hoorelbeke, K., \& De Raedt, R. (2014). Attentional 
modulation by reward and punishment cues in relation to depressive symptoms. Journal of Behavior Therapy and Experimental Psychiatry, 45(3), 351-359. https://doi.org/10.1016/j.jbtep.2014.03.003

Brooks, S., Prince, A., Stahl, D., Campbell, I. C., \& Treasure, J. (2011). A systematic review and meta-analysis of cognitive bias to food stimuli in people with disordered eating behaviour. Clinical Psychology Review, 31(1), 37-51. https://doi.org/10.1016/J.CPR.2010.09.006

Bylsma, L. M., Morris, B. H., \& Rottenberg, J. (2008). A meta-analysis of emotional reactivity in major depressive disorder. Clinical Psychology Review, 28(4), 676-691. https://doi.org/10.1016/j.cpr.2007.10.001

Chelazzi, L., Perlato, A., Santandrea, E., \& Della Libera, C. (2013). Rewards teach visual selective attention. Vision Research, 85, 58-72. https://doi.org/10.1016/j.visres.2012.12.005

Chun, M. M., Golomb, J. D., \& Turk-Browne, N. B. (2011). A taxonomy of external and internal attention. Annual Review of Psychology, 62, 73-101. https://doi.org/10.1146/annurev.psych.093008.100427

Chun, M. M., \& Turk-Browne, N. B. (2007). Interactions between attention and memory. Current Opinion in Neurobiology, 17(2), 177-184. https://doi.org/10.1016/j.conb.2007.03.005

Clark-Foos, A., \& Marsh, R. L. (2008). Recognition memory for valenced and arousing materials under conditions of divided attention. Memory, 16(5), 530-537. https://doi.org/10.1080/09658210802007493

Clasen, P. C., Wells, T. T., Ellis, A. J., \& Beevers, C. G. (2013). Attentional biases and the persistence of sad mood in major depressive disorder. Journal of Abnormal Psychology, 122(1), 74-85. https://doi.org/10.1037/a0029211

Craik, F. I. M., Eftekhari, E., \& Binns, M. A. (2018). Effects of divided attention at encoding and 
retrieval: Further data. Memory \& Cognition, 46(8), 1263-1277. https://doi.org/10.3758/s13421-018-0835-3

Cristea, I. A., Kok, R. N., \& Cuijpers, P. (2015). Efficacy of cognitive bias modification interventions in anxiety and depression: Meta-analysis. British Journal of Psychiatry, 206(1), 7-16. https://doi.org/10.1192/bjp.bp.114.146761

Daches, S., Mor, N., \& Hertel, P. (2019). Training to Inhibit Negative Content Affects Memory and Rumination. Cognitive Therapy and Research, 1-10. https://doi.org/10.1007/s10608019-10023-0

Davis, M. L., Rosenfield, D., Bernstein, A., Zvielli, A., Reinecke, A., Beevers, C. G., ... Smits, J. A. J. (2016). Attention bias dynamics and symptom severity during and following CBT for social anxiety disorder. Journal of Consulting and Clinical Psychology, 84(9), 795-802. https://doi.org/10.1037/ccp0000125

De Lissnyder, E., Koster, E. H. W. E. H. W., Derakhshan, N., De Raedt, R., Press, P. P., De Lissnyder, E., ... De Raedt, R. (2010). The association between depressive symptoms and executive control impairments in response to emotional and non-emotional information. Cognition \& Emotion, 24(2), 264-280. https://doi.org/10.1080/02699930903378354

De Raedt, R., \& Koster, E. H. W. (2010). Understanding vulnerability for depression from a cognitive neuroscience perspective: A reappraisal of attentional factors and a new conceptual framework. Cognitive, Affective, \& Behavioral Neuroscience, 10(1), 50-70. https://doi.org/10.3758/CABN.10.1.50

deBettencourt, M. T., Keene, P. A., Awh, E., \& Vogel, E. K. (2019). Real-time triggering reveals concurrent lapses of attention and working memory. Nature Human Behaviour, 3(8), 808816. https://doi.org/10.1038/s41562-019-0606-6

Della Libera, C., \& Chelazzi, L. (2009). Learning to Attend and to Ignore Is a Matter of Gains 
and Losses. Psychological Science, 20(6), 778-784. https://doi.org/10.1111/j.14679280.2009.02360.x

Disner, S. G., Beevers, C. G., Haigh, E. A. P., \& Beck, A. T. (2011). Neural mechanisms of the cognitive model of depression, 12(August). https://doi.org/10.1038/nrn3027

Dixon, M. L., Fox, K. C. R., \& Christoff, K. (2014). A framework for understanding the relationship between externally and internally directed cognition. Neuropsychologia, 62, 321-330. https://doi.org/10.1016/j.neuropsychologia.2014.05.024

Dolcos, F., Katsumi, Y., Moore, M., Berggren, N., de Gelder, B., Derakshan, N., ... Dolcos, S. (2019). Neural Correlates of Emotion-Attention Interactions: From Perception, Learning and Memory to Individual Differences and Training Interventions. Neuroscience \& Biobehavioral Reviews. https://doi.org/10.1016/j.neubiorev.2019.08.017

Dudukovic, N. M., DuBrow, S., \& Wagner, A. D. (2009). Attention during memory retrieval enhances future remembering. Memory \& Cognition, 37(7), 953-961. https://doi.org/10.3758/MC.37.7.953

Dudukovic, N. M., \& Wagner, A. D. (2006). Attending to Remember and Remembering to Attend. Neuron, 49(6), 784-787. https://doi.org/10.1016/j.neuron.2006.03.008

Ellenbogen, M. A., Schwartzman, A. E., Stewart, J., \& Walker, C.-D. C.-D. (2002). Stress and selective attention: The interplay of mood,cortisol levels, and emotional information processing. Psychophysiology, 39(6), 723-732. https://doi.org/10.1017/S0048577202010739

Ellis, A. J., Beevers, C. G., \& Wells, T. T. (2011). Attention allocation and incidental recognition of emotional information in dysphoria. Cognitive Therapy and Research, 35(5), 425-433. https://doi.org/10.1007/s10608-010-9305-3

Everaert, J., Bronstein, M. V., Cannon, T. D., \& Joormann, J. (2018). Looking through tinted glasses: Depression and social anxiety are related to both interpretation biases and inflexible 
negative interpretations. Clinical Psychological Science, 6(4), 517-528. https://doi.org/10.1177/2167702617747968

Everaert, J., Duyck, W., \& Koster, E. H. W. (2014). Attention, interpretation, and memory biases in subclinical depression: A proof-of-principle test of the combined cognitive biases hypothesis. Emotion, 14(2), 331-340. https://doi.org/10.1037/a0035250

Everaert, J., Duyck, W., \& Koster, E. H. W. (2015). Emotionally biased cognitive processes: The weakest link predicts prospective changes in depressive symptom severity. PLoS ONE, 10(5), e0124457. https://doi.org/10.1371/journal.pone.0124457

Everaert, J., Grahek, I., \& Koster, E. H. W. (2017). Individual differences in cognitive control over emotional material modulate cognitive biases linked to depressive symptoms. Cognition and Emotion, 31(4), 736-746. https://doi.org/10.1080/02699931.2016.1144562

Everaert, J., \& Joormann, J. (2019). Emotion regulation in anxiety and depression: A network approach to model relations among individual symptoms, reappraisal, and repetitive negative thinking. Clinical Psychological Science.

Everaert, J., \& Koster, E. H. W. (2015). Interactions among emotional attention, encoding, and retrieval of ambiguous information: An eye-tracking study. Emotion, 15(5), 539-543. https://doi.org/10.1037/emo0000063

Everaert, J., Koster, E. H. W., \& Derakshan, N. (2012). The combined cognitive bias hypothesis in depression. Clinical Psychology Review, 32(5), 413-424. https://doi.org/10.1016/j.cpr.2012.04.003

Everaert, J., Mogoaşe, C., David, D., \& Koster, E. H. W. (2015). Attention bias modification via single-session dot-probe training: Failures to replicate. Journal of Behavior Therapy and Experimental Psychiatry, 49, 5-12. article. https://doi.org/10.1016/j.jbtep.2014.10.011 Everaert, J., Podina, I. R., \& Koster, E. H. W. (2017). A comprehensive meta-analysis of 
interpretation biases in depression. Clinical Psychology Review, 58, 33-48. https://doi.org/10.1016/j.cpr.2017.09.005

Eysenck, M. W., Derakshan, N., Santos, R., \& Calvo, M. G. (2007). Anxiety and cognitive performance: Attentional control theory. Emotion, 7(2), 336-353. https://doi.org/10.1037/1528-3542.7.2.336

Fernandes, M. A., \& Moscovitch, M. (2002). Factors modulating the effect of divided attention during retrieval of words. Memory \& Cognition, 30(5), 731-744. https://doi.org/10.3758/BF03196429

Field, M., Munafò, M. R., \& Franken, I. H. A. (2009). A meta-analytic investigation of the relationship between attentional bias and subjective craving in substance abuse. Psychological Bulletin, 135(4), 589-607. https://doi.org/10.1037/a0015843

Fougnie, D. (2008). The relationship between attention and working memory. New Research on Short-Term Memory. https://doi.org/10.3389/conf.fnhum.2011.207.00576

Gaddy, M. A., \& Ingram, R. E. (2014). A meta-analytic review of mood-congruent implicit memory in depressed mood. Clinical Psychology Review, 34(5), 402-416. https://doi.org/10.1016/j.cpr.2014.06.001

Gibb, B. E., Alloy, L. B., Abramson, L. Y., Beevers, C. G., \& Miller, I. W. (2004). Cognitive Vulnerability to Depression: A Taxometric Analysis. Journal of Abnormal Psychology, 113(1), 81-89. https://doi.org/10.1037/0021-843X.113.1.81

Goeleven, E., Raedt, R. De, Baert, S., Koster, E. H. W., De Raedt, R., Baert, S., ... Koster, E. H. W. (2006). Deficient inhibition of emotional information in depression. Journal of Affective Disorders, 93(1-3), 149-157. https://doi.org/10.1016/j.jad.2006.03.007

Gotlib, I. H., \& Joormann, J. (2010). Cognition and depression: Current status and future directions. Annual Review of Clinical Psychology, 6(1), 285-312. 
https://doi.org/10.1146/annurev.clinpsy.121208.131305

Gotlib, I. H., Kasch, K. L., Traill, S., Joormann, J., Arnow, B. A., \& Johnson, S. L. (2004). Coherence and Specificity of Information-Processing Biases in Depression and Social Phobia. Journal of Abnormal Psychology, 113(3), 386-398. https://doi.org/10.1037/0021843X.113.3.386

Grahek, I., Everaert, J., Krebs, R., \& Koster, E. H. W. (2018). Cognitive control in depression: Towards clinical models informed by cognitive neuroscience. Clinical Psychological Science.

Guerin, S. A., Robbins, C. A., Gilmore, A. W., \& Schacter, D. L. (2012). Interactions between Visual Attention and Episodic Retrieval: Dissociable Contributions of Parietal Regions during Gist-Based False Recognition. Neuron, 75(6), 1122-1134. https://doi.org/10.1016/j.neuron.2012.08.020

Hallion, L. S. S., \& Ruscio, A. M. M. (2011). A meta-analysis of the effect of cognitive bias modification on anxiety and depression. Psychological Bulletin, 137(6), 940-958. https://doi.org/10.1037/a0024355 2011-13412-001 [pii]

Hankin, B. L. (2008). Stability of cognitive vulnerabilities to depression: A short-term prospective multiwave study. Journal of Abnormal Psychology, 117(2), 324-333. https://doi.org/10.1037/0021-843X.117.2.324

Hankin, B. L. (2012). Future directions in vulnerability to depression among youth: Integrating risk factors and processes across multiple levels of analysis. Journal of Clinical Child \& Adolescent Psychology, 41(5), 695-718. https://doi.org/10.1080/15374416.2012.711708

Hasson, U., Chen, J., \& Honey, C. J. (2015). Hierarchical process memory: memory as an integral component of information processing. Trends in Cognitive Sciences, 19(6), 304313. https://doi.org/10.1016/j.tics.2015.04.006 
Heeren, A., \& McNally, R. J. (2016). An integrative network approach to social anxiety disorder: The complex dynamic interplay among attentional bias for threat, attentional control, and symptoms. Journal of Anxiety Disorders, 42, 95-104. https://doi.org/10.1016/J.JANXDIS.2016.06.009

Hertel, P. T., \& Brozovich, F. (2010). Cognitive habits and memory distortions in anxiety and depression. Current Directions in Psychological Science, 19(3), 155-160. https://doi.org/10.1177/0963721410370137

Hertel, P. T., Brozovich, F., Joormann, J., \& Gotlib, I. H. (2008). Biases in interpretation and memory in generalized social phobia. Journal of Abnormal Psychology, 117(2), 278-288. https://doi.org/10.1037/0021-843X.117.2.278

Hertel, P. T., \& Mathews, A. (2011). Cognitive bias modification: Past perspectives, current findings, and future applications. Perspectives on Psychological Science, 6(6), 521-536. https://doi.org/10.1177/1745691611421205

Hertel, P. T., Maydon, A., Cottle, J., \& Vrijsen, J. N. (2017). Cognitive Bias Modification. Clinical Psychological Science, 5(1), 122-130. https://doi.org/10.1177/2167702616649366

Hickey, C., \& van Zoest, W. (2013). Reward-associated stimuli capture the eyes in spite of strategic attentional set. Vision Research, 92, 67-74. https://doi.org/10.1016/j.visres.2013.09.008

Hicks, J. L., \& Marsh, R. L. (2000). Toward specifying the attentional demands of recognition memory. Journal of Experimental Psychology: Learning, Memory, and Cognition, 26(6), 1483-1498. https://doi.org/10.1037/0278-7393.26.6.1483

Hirsch, C. R., Clark, D. M., \& Mathews, A. (2006). Imagery and interpretations in social phobia: Support for the combined cognitive biases hypothesis. Behavior Therapy, 37(3), 223-236. https://doi.org/10.1016/j.beth.2006.02.001 
Hirsch, C. R., Meeten, F., Krahé, C., \& Reeder, C. (2016). Resolving ambiguity in emotional disorders: The nature and role of interpretation biases. Annual Review of Clinical Psychology, 12(1), 281-305. https://doi.org/10.1146/annurev-clinpsy-021815-093436

Holmes, E. A., Lang, T. J., \& Deeprose, C. (2009). Mental imagery and emotion in treatment across disorders: Using the example of depression. Cognitive Behaviour Therapy, 38, 21-28. https://doi.org/10.1080/16506070902980729

Hoorelbeke, K., Van den Bergh, N., Wichers, M., \& Koster, E. H. W. (2019). Between vulnerability and resilience: A network analysis of fluctuations in cognitive risk and protective factors following remission from depression. Behaviour Research and Therapy, 116, 1-9. https://doi.org/10.1016/j.brat.2019.01.007

Houben, M., Van Den Noortgate, W., \& Kuppens, P. (2015). The relation between short-term emotion dynamics and psychological well-being: A meta-analysis. Psychological Bulletin, 141(4), 901-930. https://doi.org/10.1037/a0038822

Huppert, J. D., Pasupuleti, R. V., Foa, E. B., \& Mathews, A. (2007). Interpretation biases in social anxiety: Response generation, response selection, and self-appraisals. Behaviour Research and Therapy, 45(7), 1505-1515. https://doi.org/10.1016/j.brat.2007.01.006

Hutchinson, J. B., \& Turk-Browne, N. B. (2012). Memory-guided attention: Control from multiple memory systems. Trends in Cognitive Sciences, 16(12), 576-579. https://doi.org/10.1016/j.tics.2012.10.003

Iacoviello, B. M., Wu, G., Abend, R., Murrough, J. W., Feder, A., Fruchter, E., ... Charney, D. S. (2014). Attention bias variability and symptoms of posttraumatic stress disorder. Journal of Traumatic Stress, 27(2), 232-239. https://doi.org/10.1002/jts.21899

Ingram, R. E. (1984). Toward an information-processing analysis of depression. Cognitive Therapy and Research, 8(5), 443-477. https://doi.org/10.1007/BF01173284 
Jacoby, L. L. (1991). A process dissociation framework: Separating automatic from intentional uses of memory. Journal of Memory and Language, 30(5), 513-541. https://doi.org/10.1016/0749-596X(91)90025-F

Jiang, M. Y. W., \& Vartanian, L. R. (2012). Attention and memory biases toward body-related images among restrained eaters. Body Image, 9(4), 503-509. https://doi.org/10.1016/j.bodyim.2012.06.007

Johnson, S. L., Joormann, J., \& Gotlib, I. H. (2007). Does processing of emotional stimuli predict symptomatic improvement and diagnostic recovery from major depression? Emotion, 7(1), 201-206. https://doi.org/10.1037/1528-3542.7.1.201

Joormann, J. (2004). Attentional bias in dysphoria: The role of inhibitory processes. Cognition \& Emotion, 18(1), 125-147. https://doi.org/10.1080/02699930244000480

Joormann, J. (2010). Cognitive inhibition and emotion regulation in depression. Current Directions in Psychological Science, 19(3), 161-166. https://doi.org/10.1177/0963721410370293

Joormann, J., \& Siemer, M. (2004). Memory Accessibility, Mood Regulation, and Dysphoria: Difficulties in Repairing Sad Mood With Happy Memories? Journal of Abnormal Psychology, 113(2), 179-188. https://doi.org/10.1037/0021-843X.113.2.179

Joormann, J., \& Vanderlind, W. M. (2014). Emotion regulation in depression: The role of biased cognition and reduced cognitive control. Clinical Psychological Science, 2(4), 402-421. https://doi.org/10.1177/2167702614536163

Joormann, J., Yoon, K. L., \& Zetsche, U. (2007). Cognitive inhibition in depression. Applied and Preventive Psychology, 12(3), 128-139. https://doi.org/10.1016/j.appsy.2007.09.002

Kashdan, T. B., \& Rottenberg, J. (2010). Psychological flexibility as a fundamental aspect of health. Clinical Psychology Review, 30(7), 865-878. 
https://doi.org/10.1016/j.cpr.2010.03.001

Kim, H. (2019). Neural correlates of explicit and implicit memory at encoding and retrieval: A unified framework and meta-analysis of functional neuroimaging studies. Biological Psychology. https://doi.org/10.1016/J.BIOPSYCHO.2019.04.006

Kizilirmak, J. M., Rösler, F., \& Khader, P. H. (2012). Control processes during selective longterm memory retrieval. NeuroImage, 59(2), 1830-1841. https://doi.org/10.1016/j.neuroimage.2011.08.041

Kolnes, M., Naar, R., Allik, J., \& Uusberg, A. (2019). Does goal congruence dilate the pupil over and above goal relevance? Neuropsychologia, 107217. https://doi.org/10.1016/J.NEUROPSYCHOLOGIA.2019.107217

Koster, E. H. W., \& Bernstein, A. (2015). Introduction to the special issue on Cognitive bias modification: Taking a step back to move forward? Journal of Behavior Therapy and Experimental Psychiatry, 49, 1-4. https://doi.org/10.1016/j.jbtep.2015.05.006

Koster, E. H. W., Crombez, G., Van Damme, S., Verschuere, B., De Houwer, J., Damme, S. Van, \& Verschuere, B. (2004). Does imminent threat capture and hold attention? Emotion, 4(3), 312-317. https://doi.org/10.1037/1528-3542.4.3.312

Koster, E. H. W., De Lissnyder, E., Derakshan, N., \& De Raedt, R. (2011). Understanding depressive rumination from a cognitive science perspective: the impaired disengagement hypothesis. Clinical Psychology Review, 31(1), 138-145. https://doi.org/10.1016/j.cpr.2010.08.005

Koster, E. H. W., De Raedt, R., Leyman, L., \& De Lissnyder, E. (2010). Mood-congruent attention and memory bias in dysphoria: Exploring the coherence among informationprocessing biases. Behaviour Research and Therapy, 48(3), 219-225. https://doi.org/10.1016/j.brat.2009.11.004 
Koster, E. H. W., Hoorelbeke, K., Onraedt, T., Owens, M., \& Derakshan, N. (2017). Cognitive control interventions for depression: A systematic review of findings from training studies. Clinical Psychology Review, 53, 79-92. https://doi.org/10.1016/j.cpr.2017.02.002

Kotov, R., Krueger, R. F., \& Watson, D. (2018). A paradigm shift in psychiatric classification: the Hierarchical Taxonomy Of Psychopathology (HiTOP). World Psychiatry, 17(1), 24-25. https://doi.org/10.1002/wps.20478

Kraemer, H. C., Stice, E., Kazdin, A., Offord, D., \& Kupfer, D. (2001). How do risk factors work together? Mediators, moderators, and independent, overlapping, and proxy risk factors. American Journal of Psychiatry, 158(6), 848-856. https://doi.org/10.1176/appi.ajp.158.6.848

Kruijne, W., \& Meeter, M. (2016). Implicit short- and long-term memory direct our gaze in visual search. Attention, Perception, \& Psychophysics, 78(3), 761-773. https://doi.org/10.3758/s13414-015-1021-3

Kruijt, A. W., Field, A. P., Fox, E., Thompson, E., Reinecke, A., \& Beevers, C. (2016). Capturing dynamics of biased attention: Are new attention variability measures the way forward. PLoS ONE, 11(11), 1-22. https://doi.org/10.1371/journal.pone.0166600

Kube, T., Rief, W., Gollwitzer, M., Gärtner, T., \& Glombiewski, J. A. (2018). Why dysfunctional expectations in depression persist - Results from two experimental studies investigating cognitive immunization. Psychological Medicine, 1-13. https://doi.org/10.1017/S0033291718002106

Lau, J. Y. F., \& Waters, A. M. (2017). Annual Research Review: An expanded account of information-processing mechanisms in risk for child and adolescent anxiety and depression. Journal of Child Psychology and Psychiatry, 58(4), 387-407. https://doi.org/10.1111/jcpp.12653 
Lazarov, A., Pine, D. S., \& Bar-Haim, Y. (2017). Gaze-Contingent Music Reward Therapy for Social Anxiety Disorder: A Randomized Controlled Trial. American Journal of Psychiatry, 174(7), 649-656. https://doi.org/10.1176/appi.ajp.2016.16080894

Lazarov, A., Suarez-Jimenez, B., Tamman, A., Falzon, L., Zhu, X., Edmondson, D. E., \& Neria, Y. (2019). Attention to threat in posttraumatic stress disorder as indexed by eye-tracking indices: a systematic review. Psychological Medicine, 49, 705-726. https://doi.org/10.1017/S0033291718002313

Lei, H., Nahum-Shani, I., Lynch, K., Oslin, D., \& Murphy, S. A. (2012). A \&quot;SMART\&quot; Design for Building Individualized Treatment Sequences. Annual Review of Clinical Psychology, 8(1), 21-48. https://doi.org/10.1146/annurev-clinpsy$032511-143152$

LeMoult, J., Colich, N., Joormann, J., Singh, M. K., Eggleston, C., \& Gotlib, I. H. (2017). Interpretation bias training in depressed adolescents: Near- and far-transfer effects. Journal of Abnormal Child Psychology, 1-9. https://doi.org/10.1007/s10802-017-0285-6

LeMoult, J., \& Gotlib, I. H. (2018). Depression: A cognitive perspective. Clinical Psychology Review. https://doi.org/10.1016/j.cpr.2018.06.008

LeMoult, J., \& Joormann, J. (2012). Attention and memory biases in social anxiety disorder: The role of comorbid depression. Cognitive Therapy and Research, 36(1), 47-57. https://doi.org/10.1007/s10608-010-9322-2

Levens, S. M., \& Gotlib, I. H. (2010). Updating positive and negative stimuli in working memory in depression. Journal of Experimental Psychology. General, 139(4), 654-664. https://doi.org/10.1037/a0020283

Liu, R. T., McArthur, B. A., Burke, T. A., Hamilton, J. L., Mac Giollabhui, N., Stange, J. P., ... Alloy, L. B. (2018). A Latent Structure Analysis of Cognitive Vulnerability to Depression in 
Adolescence. Behavior Therapy. https://doi.org/10.1016/J.BETH.2018.11.004

Lozito, J. P., \& Mulligan, N. W. (2010). Exploring the role of attention during implicit memory retrieval. Journal of Memory and Language, 63(3), 387-399.

https://doi.org/10.1016/j.jml.2010.06.007

Luck, S. J., \& Gold, J. M. (2008). The Construct of Attention in Schizophrenia. Biological Psychiatry, 64(1), 34-39. https://doi.org/10.1016/J.BIOPSYCH.2008.02.014

MacLeod, C., \& Mathews, A. (2012). Cognitive bias modification approaches to anxiety. Annual Review of Clinical Psychology, 8, 189-217. https://doi.org/10.1146/annurev-clinpsy032511-143052

Maddox, G. B., Naveh-Benjamin, M., Old, S., \& Kilb, A. (2012). The role of attention in the associative binding of emotionally arousing words. Psychonomic Bulletin \& Review, 19(6), 1128-1134. https://doi.org/10.3758/s13423-012-0315-x

Marchetti, I., Everaert, J., Dainer-Best, J., Loeys, T., Beevers, C. G., \& Koster, E. H. W. (2018). Specificity and overlap of attention and memory biases in depression. Journal of Affective Disorders, 225, 404-412. https://doi.org/10.1016/j.jad.2017.08.037

Mathews, A., \& Macleod, C. M. (2005). Cognitive vulnerability to emotional disorders. Annual Review of Clinical Psychology, 1(1), 167-195. https://doi.org/10.1146/annurev.clinpsy.1.102803.143916

Matt, G. E., Vázquez, C., \& Campbell, W. K. (1992). Mood-congruent recall of affectively toned stimuli: A meta-analytic review. Clinical Psychology Review, 12(2), 227-255. https://doi.org/10.1016/0272-7358(92)90116-P

McNally, R. J. (2019). Attentional bias for threat: Crisis or opportunity? Clinical Psychology Review, 69, 4-13. https://doi.org/10.1016/j.cpr.2018.05.005

Mehu, M., \& Scherer, K. R. (2015). The appraisal bias model of cognitive vulnerability to 
depression. Emotion Review, 7(3), 272-279. https://doi.org/10.1177/1754073915575406

Mennen, A. C., Norman, K. A., \& Turk-Browne, N. B. (2019). Attentional bias in depression: understanding mechanisms to improve training and treatment. Current Opinion in Psychology. https://doi.org/10.1016/J.COPSYC.2019.07.036

Mitte, K. (2008). Memory bias for threatening information in anxiety and anxiety disorders: A meta-analytic review. Psychological Bulletin, 134(6), 886-911. https://doi.org/10.1037/a0013343

Miyake, A., \& Friedman, N. P. (2012). The nature and organization of individual differences in executive functions. Current Directions in Psychological Science, 21(1), 8-14. https://doi.org/10.1177/0963721411429458

Mogg, K., \& Bradley, B. P. (2018). Anxiety and Threat-Related Attention: CognitiveMotivational Framework and Treatment. Trends in Cognitive Sciences, 22(3), 225-240. https://doi.org/10.1016/j.tics.2018.01.001

Morrison, A. S., \& Heimberg, R. G. (2013). Social anxiety and social anxiety disorder. Annual Review of Clinical Psychology, 9(1), 249-274. https://doi.org/10.1146/annurev-clinpsy$050212-185631$

Nahum-Shani, I., Smith, S. N., Spring, B. J., Collins, L. M., Witkiewitz, K., Tewari, A., \& Murphy, S. A. (2018). Just-in-Time Adaptive Interventions (JITAIs) in Mobile Health: Key Components and Design Principles for Ongoing Health Behavior Support. Annals of Behavioral Medicine, 52(6), 446-462. https://doi.org/10.1007/s12160-016-9830-8

Naveh-Benjamin, M., Kilb, A., \& Fisher, T. (2006). Concurrent task effects on memory encoding and retrieval: Further support for an asymmetry. Memory \& Cognition, 34(1), 90-101. https://doi.org/10.3758/BF03193389

Neisser, U. (1967). Cognitive psychology. East Norwalk: Appleton Century Crofts. 
Newby, J. M., Lang, T., Werner-Seidler, A., Holmes, E., \& Moulds, M. L. (2014). Alleviating distressing intrusive memories in depression: A comparison between computerised cognitive bias modification and cognitive behavioural education. Behaviour Research and Therapy, 56(1), 60-67. https://doi.org/10.1016/j.brat.2014.03.001

Orchard, F., \& Reynolds, S. (2018). The combined influence of cognitions in adolescent depression: Biases of interpretation, self-evaluation, and memory. British Journal of Clinical Psychology, 57(4), 420-435. https://doi.org/10.1111/bjc.12184

Ouimet, A. J., Gawronski, B., \& Dozois, D. J. A. (2009). Cognitive vulnerability to anxiety: A review and an integrative model. Clinical Psychology Review, 29(6), 459-470. https://doi.org/10.1016/j.cpr.2009.05.004

Pe, M. L., Kircanski, K., Thompson, R. J., Bringmann, L. F., Tuerlinckx, F., Mestdagh, M., ... Gotlib, I. H. (2015). Emotion-Network Density in Major Depressive Disorder. Clinical Psychological Science, 3(2), 292-300. https://doi.org/10.1177/2167702614540645

Peckham, A. D., McHugh, R. K., \& Otto, M. W. (2010). A meta-analysis of the magnitude of biased attention in depression. Depression and Anxiety, 27(12), 1135-1142. https://doi.org/10.1002/da.20755

Peschard, V., \& Philippot, P. (2016). Social anxiety and information processing biases: An integrated theoretical perspective. Cognition and Emotion, 30(4), 762-777. https://doi.org/10.1080/02699931.2015.1028335

Petersen, S. ., \& Posner, M. (2012). The attention system of the human brain: 20 years after. Annual Review of Neuroscience, 21(35), 73-89. https://doi.org/10.1146/annurev-neuro062111-150525.The

Platt, B., Waters, A. M., Schulte-Koerne, G., Engelmann, L., \& Salemink, E. (2017). A review of cognitive biases in youth depression: attention, interpretation and memory. Cognition and 
Emotion, 31(3), 462-483. https://doi.org/10.1080/02699931.2015.1127215

Polyn, S. M., \& Kahana, M. J. (2008). Memory search and the neural representation of context. Trends in Cognitive Sciences, 12(1), 24-30. https://doi.org/10.1016/j.tics.2007.10.010

Polyn, S. M., Norman, K. A., \& Kahana, M. J. (2009). A context maintenance and retrieval model of organizational processes in free recall. Psychological Review, 116(1), 129-156. https://doi.org/10.1037/a0014420

Pottage, C. L., \& Schaefer, a. (2012). Visual attention and emotional memory: recall of aversive pictures is partially mediated by concurrent task performance. Emotion, 12(1), 33-38. https://doi.org/10.1037/a0024574

Price, R. B., Rosen, D., Siegle, G. J., Ladouceur, C. D., Tang, K., Allen, K. B., ... Silk, J. S. (2016). From anxious youth to depressed adolescents: Prospective prediction of 2-year depression symptoms via attentional bias measures. Journal of Abnormal Psychology, 125(2), 267-278. https://doi.org/10.1037/abn0000127

Quinn, M. E., \& Joormann, J. (2015). Stress-induced changes in executive control are associated with depression symptoms: Examining the role of rumination. Clinical Psychological Science, 3(4), 628-636. https://doi.org/10.1177/2167702614563930

Reinhart, R. M. G., McClenahan, L. J., \& Woodman, G. F. (2016). Attention's accelerator. Psychological Science, 27(6), 790-798. https://doi.org/10.1177/0956797616636416

Reynolds, M., \& Brewin, C. R. (1999). Intrusive memories in depression and posttraumatic stress disorder. Behaviour Research and Therapy, 37(3), 201-215. https://doi.org/10.1016/S00057967(98)00132-6

Rodebaugh, T. L., Scullin, R. B., Langer, J. K., Dixon, D. J., Huppert, J. D., Bernstein, A., ... Lenze, E. J. (2016). Unreliability as a threat to understanding psychopathology: The cautionary tale of attentional bias. Journal of Abnormal Psychology, 125(6), 840-851. 
https://doi.org/10.1037/abn0000184

Rohrer, D., \& Pashler, H. E. (2003). Concurrent task effects on memory retrieval. Psychonomic Bulletin \& Review, 10(1), 96-103. https://doi.org/10.3758/BF03196472

Ruimi, L., Hadash, Y., Zvielli, A., Amir, I., Goldstein, P., \& Bernstein, A. (2018). MetaAwareness of Dysregulated Emotional Attention. Clinical Psychological Science, 6(5), 658670. https://doi.org/10.1177/2167702618776948

Salem, T., Winer, E. S., \& Nadorff, M. R. (2017). Combined behavioural markers of cognitive biases are associated with anhedonia. Cognition \& Emotion, 31, 1-9. https://doi.org/10.1080/02699931.2017.1307808

Sanchez-Lopez, A., De Raedt, R., van Put, J., \& Koster, E. H. W. (2019). A novel process-based approach to improve resilience: Effects of computerized mouse-based (gaze)contingent attention training (MCAT) on reappraisal and rumination. Behaviour Research and Therapy, 118, 110-120. https://doi.org/10.1016/j.brat.2019.04.005

Sanchez, A., Duque, A., Romero, N., \& Vazquez, C. (2017). Disentangling the interplay among cognitive biases: Evidence of combined effects of attention, interpretation and autobiographical memory in depression. Cognitive Therapy and Research, (May). https://doi.org/10.1007/s10608-017-9858-5

Sanchez, A., Everaert, J., \& Koster, E. H. W. (2016). Attention training through gaze-contingent feedback: Effects on reappraisal and negative emotions. Emotion, 16(7), 1074-1085. https://doi.org/10.1037/emo0000198

Sanchez, A., Everaert, J., van Put, J., De Raedt, R., \& Koster, E. H. W. (2019). Eye-gaze contingent attention training (ECAT):Examining the causal role of attention regulation in reappraisal and rumination. Biological Psychology, 142, 116-125. https://doi.org/10.1016/j.biopsycho.2019.01.017 
Sanchez, A., Vazquez, C., Marker, C., LeMoult, J., \& Joormann, J. (2013). Attentional disengagement predicts stress recovery in depression: an eye-tracking study. Journal of Abnormal Psychology, 122(2), 303-313. https://doi.org/10.1037/a0031529

Sanislow, C. A., Pine, D. S., Quinn, K. J., Kozak, M. J., Garvey, M. A., Heinssen, R. K., ... Cuthbert, B. N. (2010). Developing constructs for psychopathology research: Research domain criteria. Journal of Abnormal Psychology, 119(4), 631-639. https://doi.org/10.1037/a0020909

Savulich, G., Shergill, S., \& Yiend, J. (2012). Biased Cognition in Psychosis. Journal of Experimental Psychopathology, 3(4), jep.016711. https://doi.org/10.5127/jep.016711

Schäfer, J., Zvielli, A., Höfler, M., Wittchen, H.-U., \& Bernstein, A. (2018). Trauma, attentional dysregulation, and the development of posttraumatic stress: An investigation of risk pathways. Behaviour Research and Therapy, 102, 60-66. https://doi.org/10.1016/j.brat.2018.01.004

Schippell, P. L., Vasey, M. W., Cravens-Brown, L. M., \& Bretveld, R. A. (2003). Suppressed Attention to Rejection, Ridicule, and Failure Cues: A Unique Correlate of Reactive but Not Proactive Aggression in Youth. Journal of Clinical Child \& Adolescent Psychology, 32(1), 40-55. https://doi.org/10.1207/S15374424JCCP3201_05

Schmidt, L. J., Belopolsky, A. V., \& Theeuwes, J. (2015). Attentional capture by signals of threat. Cognition and Emotion, 29(4), 687-694. https://doi.org/10.1080/02699931.2014.924484

Schmukle, S. C. (2005). Unreliability of the dot probe task. European Journal of Personality, 19(7), 595-605. https://doi.org/10.1002/per.554

Schnyer, D. M., Beevers, C. G., DeBettencourt, M. T., Sherman, S. M., Cohen, J. D., Norman, K. A., \& Turk-Browne, N. B. (2015). Neurocognitive therapeutics: from concept to application 
in the treatment of negative attention bias. Biology of Mood \{\&\} Anxiety Disorders, 5(1), 1. https://doi.org/10.1186/s13587-015-0016-y

Schupp, H. T., Kirmse, U., Schmälzle, R., Flaisch, T., \& Renner, B. (2016). Newly-formed emotional memories guide selective attention processes: Evidence from event-related potentials. Scientific Reports, 6(1), 28091. https://doi.org/10.1038/srep28091

Schweizer, S., Grahn, J., Hampshire, A., Mobbs, D., \& Dalgleish, T. (2013). Training the emotional brain: Improving affective control through emotional working memory training. Annals of Internal Medicine, 158(6), 5301-5311. https://doi.org/10.1523/JNEUROSCI.2593-12.2013

Schweizer, S., Hampshire, A., \& Dalgleish, T. (2011). Extending Brain-Training to the Affective Domain: Increasing Cognitive and Affective Executive Control through Emotional Working Memory Training. PLoS ONE, 6(9), e24372. https://doi.org/10.1371/journal.pone.0024372

Schweizer, S., Satpute, A. B., Atzil, S., Field, A., Hitchcock, C., Black, M., ... Dalgleish, T. (2019). The impact of affective information on working memory: a pair of meta-analytic reviews of behavioral and neuroimaging evidence. Psychological Bulletin. https://doi.org/10.31234/OSF.IO/VXRMP

Sears, C., Quigley, L., Fernandez, A., Newman, K., \& Dobson, K. (2018). The reliability of attentional biases for emotional images measured using a free-viewing eye-tracking paradigm. Behavior Research Methods, 1-13. https://doi.org/10.3758/s13428-018-1147-z

Soto, D., Hodsoll, J., Rotshtein, P., \& Humphreys, G. W. (2008). Automatic guidance of attention from working memory. Trends in Cognitive Sciences, 12(9), 342-348. https://doi.org/10.1016/j.tics.2008.05.007

Stange, J. P., Alloy, L. B., \& Fresco, D. M. (2017). Inflexibility as a vulnerability to depression: A systematic qualitative review. Clinical Psychology: Science and Practice, 24(3), 245-276. 
https://doi.org/10.1111/cpsp.12201

Stokes, M., \& Spaak, E. (2016). The importance of single-trial analyses in cognitive neuroscience. Trends in Cognitive Sciences, 20(7), 483-486.

https://doi.org/10.1016/j.tics.2016.05.008

Suárez-Suárez, S., Rodríguez Holguín, S., Cadaveira, F., Nobre, A. C., \& Doallo, S. (2019).

Punishment-related memory-guided attention: Neural dynamics of perceptual modulation. Cortex, 115, 231-245. https://doi.org/10.1016/J.CORTEX.2019.01.029

Summerfield, J. J., Lepsien, J., Gitelman, D. R., Mesulam, M. M., \& Nobre, A. C. (2006).

Orienting attention based on long-term memory experience. Neuron, 49(6), 905-916. https://doi.org/10.1016/j.neuron.2006.01.021

Summerfield, J. J., Rao, A., Garside, N., \& Nobre, A. C. (2011). Biasing perception by spatial long-term memory. Journal of Neuroscience, 31(42), 14952-14960.

https://doi.org/10.1523/JNEUROSCI.5541-10.2011

Talmi, D. (2013). Enhanced emotional memory: Cognitive and neural mechanisms. Current Directions in Psychological Science, 22(6), 430-436.

https://doi.org/10.1177/0963721413498893

Todd, R. M., \& Manaligod, M. G. M. (2017). Implicit guidance of attention: The priority state space framework. Cortex. https://doi.org/10.1016/j.cortex.2017.08.001

Tulving, E. (1985). Memory and consciousness. Canadian Psychology/Psychologie Canadienne, 26(1985), 1-12. https://doi.org/10.1037/h0080017

Turk-Browne, N. B., Golomb, J. D., \& Chun, M. M. (2013). Complementary attentional components of successful memory encoding. NeuroImage, 66, 553-562. https://doi.org/10.1016/j.neuroimage.2012.10.053

Van Ryckeghem, D. M. L., \& Vervoort, T. (2016). Towards an integrative view of cognitive 
biases in pain. European Journal of Pain, 20(8), 1201-1202. https://doi.org/10.1002/ejp.913

van Vugt, M. K., Hitchcock, P., Shahar, B., \& Britton, W. (2012). The effects of mindfulnessbased cognitive therapy on affective memory recall dynamics in depression: A mechanistic model of rumination. Frontiers in Human Neuroscience, 6(September), 1-13. https://doi.org/10.3389/fnhum.2012.00257

Voogd, E. L. De, Wiers, R. W., \& Salemink, E. (2017). Online visual search attentional bias modification for adolescents with heightened anxiety and depressive symptoms : A randomized controlled trial. Behaviour Research and Therapy, 92, 57-67. https://doi.org/10.1016/j.brat.2017.02.006

Vrijsen, J. N., Becker, E. S., Arias-Vásquez, A., van Dijk, M. K., Speckens, A., \& Oostrom, I. van. (2014). What is the contribution of different cognitive biases and stressful childhood events to the presence and number of previous depressive episodes? Psychiatry Research, 217(3), 134-142. https://doi.org/10.1016/j.psychres.2014.02.033

Vrijsen, J. N., Hertel, P. T., \& Becker, E. S. (2016). Practicing emotionally biased retrieval affects mood and establishes biased recall a week later. Cognitive Therapy and Research, 40(6), 764-773. https://doi.org/10.1007/s10608-016-9789-6

Vrijsen, J. N., Van Oostrom, I., Isaac, L., Becker, E. S., \& Speckens, A. (2014). Coherence between attentional and memory biases in sad and formerly depressed individuals. Cognitive Therapy and Research, 38(3), 334-342. https://doi.org/10.1007/s10608-013-9590-8

Waechter, S., Nelson, A. L., Wright, C., Hyatt, A., \& Oakman, J. (2014). Measuring Attentional Bias to Threat: Reliability of Dot Probe and Eye Movement Indices. Cognitive Therapy and Research, 38(3), 313-333. https://doi.org/10.1007/s10608-013-9588-2

Williams, J. M. G., Watts, C., MacLeod, C. M., Mathews, A., Williams, M. G., Watts, F. N., ... Mathews, A. (1997). Cognitive psychology and emotional disorders (second edi). 
Chichester: Wiley.

Winer, E. S., \& Salem, T. (2016). Reward devaluation: Dot-probe meta-analytic evidence of avoidance of positive information in depressed persons. Psychological Bulletin, 142(1), 1878. https://doi.org/10.1037/bul0000022

Wisco, B. E. (2009). Depressive cognition: Self-reference and depth of processing. Clinical Psychology Review, 29(4), 382-392. https://doi.org/10.1016/j.cpr.2009.03.003

Wittenborn, A. K., Rahmandad, H., Rick, J., \& Hosseinichimeh, N. (2016). Depression as a systemic syndrome: mapping the feedback loops of major depressive disorder. Psychological Medicine, 46(03), 551-562. https://doi.org/10.1017/S0033291715002044

Yonelinas, A. P., Aly, M., Wang, W. C., \& Koen, J. D. (2010). Recollection and familiarity: Examining controversial assumptions and new directions. Hippocampus, 20(11), 11781194. https://doi.org/10.1002/hipo.20864

Yuval, K., Zvielli, A., \& Bernstein, A. (2017). Attentional bias dynamics and posttraumatic stress in survivors of violent conflict and atrocities. Clinical Psychological Science, 5(1), 64-73. https://doi.org/10.1177/2167702616649349

Zvielli, A., Bernstein, A., \& Koster, E. H. W. (2014). Temporal dynamics of attentional bias. Clinical Psychological Science, 1-17. https://doi.org/10.1177/2167702614551572

Zvielli, A., Vrijsen, J. N., Koster, E. H. W., \& Bernstein, A. (2016). Attentional bias temporal dynamics in remitted depression. Journal of Abnormal Psychology, 125(6), 768-776. https://doi.org/10.1037/abn0000190 


\section{Mechanisms and features of interactions} among emotional biases in cognitive processes in depression

1. Attention bias (AB) during memory encoding modulates long-term memory (LTM) bias

2. $A B$ during memory retrieval modulates LTM bias

3. LTM bias guides the allocation of attention

4. Working memory difficulties (WM diff.) modulate attention bias - LTM bias interactions

5. Interactions among biases of cognitive processes dynamically fluctuate across time and contexts

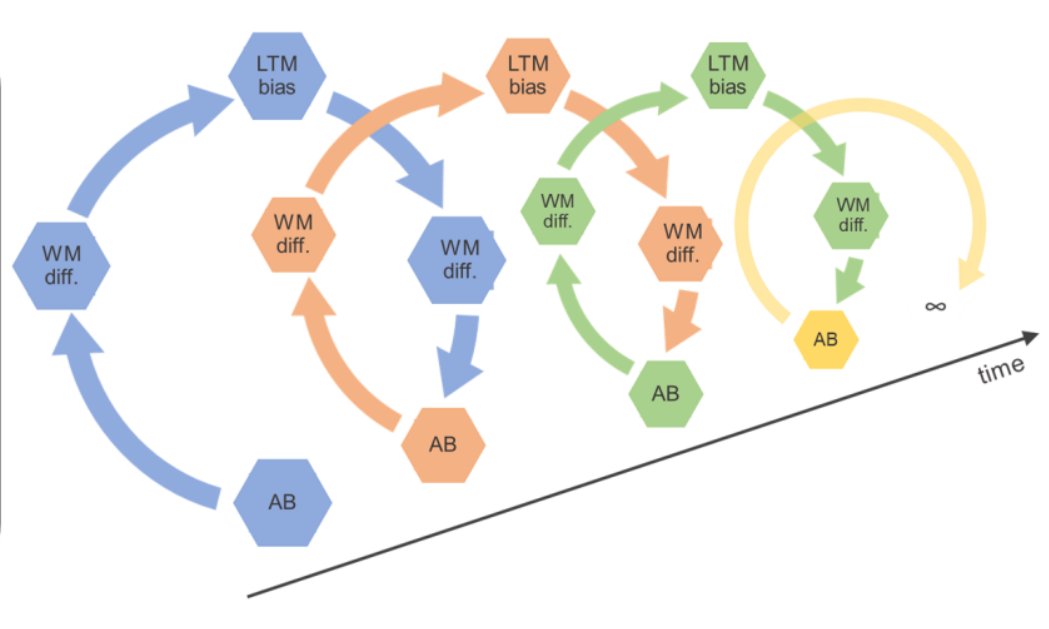

Figure 1. Schematic overview of emotional attention - memory interactions in depression. 